\title{
Analysis of a Fuel Cell Combined Heat and Power Plant Under Realistic Smart Management Scenarios
}

\author{
Andrea L. Facci ${ }^{\mathrm{a}, *}$, Stefano Ubertini ${ }^{\mathrm{a}}$ \\ ${ }^{a}$ School of Engineering (DEIM), University of Tuscia, 01100 Viterbo, Italia.
}

\begin{abstract}
Proton exchange membrane fuel cells are a promising and mature technology for combined heat and power plants. High efficiency (in particular for small size devices), practically zero pollutant emissions, noiseless operation and fast response to transient demand make these energy systems excellent prime movers for residential and commercial application. Nevertheless, due to large capital costs, their utilization and commercialization are still limited to demonstrative projects. In this scenario we are working on a research project, called AutoRe, which utilizes an automotive derivative fuel cell for a cogeneration plant to create a synergy between two non competitive industries (automotive and stationary plants) and to realize a significant economy of scale that will drastically cut the costs of fuel cell based cogenerative plants. In this paper we perform a thorough techno-economic analysis of the AutoRe (AUTomotive deRivative Energy system) power plant. A number of realistic energy management scenarios are constructed by varying the energy demand, the climatic condition, the energy cost, and the efficiency of the surrounding energy system. The control strategy is determined on an hourly basis, by minimizing the cost or the primary energy consumption through a graph based methodology. The resulting global parameters are compared to a reference scenario where electricity is acquired from the grid and heat is locally produced through a natural gas boiler. We consider 5 different building types (Office, Apartment district, Clinic, Hotel, Supermarket), 5 different climatic conditions (Hot, Cooling Based, Moderate, Heating based, Cold), and 2 different surrounding energy systems (USA and Europe). The results show that overall the proposed plant is economically sustainable and effective in reducing the energy costs and the primary energy consumption. Nevertheless, the building type and the energy prices impact on the return on investment, while the climatic condition affects the relative cost and energy variations. In the US scenario the management based on cost and primary energy minimization exhibits similar patterns. On the contrary, in Europe cost minimization might increase the primary energy consumption with respect to the reference scenario.
\end{abstract}

Keywords: Cogeneration, Distributed generation, CHP, Fuel Cells, PEM, Smart Management,

\section{Introduction}

Fuel cells (FCs) are a promising technology for satisfying the energy demand for stationary applications, in particular in the residential and commercial sectors [1-5], being particularly suited as prime movers for small cogeneration (CHP) plants $[5,6]$. In fact, $64 \%$ of the micro-cogeneration systems sold in 2012 are based on FCs [3, 7, 8]. Several features of the FCs, such as high efficiency [9], very low pollutant $\left(\mathrm{NO}_{\mathrm{x}}, \mathrm{SO}_{\mathrm{x}}\right.$, and particulate matter) emissions [10], vibration and noise-free operation [11] determine such a success. Moreover the efficiency of a FC is only marginally influenced by its size and is generally increased at part load [12], differently from traditional power generation technologies [12]. Depending on the FC technology, different fuels can be used for FCs including hydrogen [13], natural gas (NG) [14], methanol [14], and bio-fuels [1517]. Hydrogen fueled FCs are also envisaged to promote renewable sources penetration allowing long term electrical energy storage[18, 19]. All these positive aspects boost the advantages

\footnotetext{
*Corresponding author. Tel.: +390761 357676.

Email addresses: andrea . facci@unitus. it (Andrea L. Facci), stefano.ubertini@unitus.it (Stefano Ubertini)
}

of combined heat and power that are already widely acknowledged and include: (i) increased overall efficiency compared to separate production $[12,20]$; (ii) reduction of pollutant and green house gases emissions [20, 21]; (iii) deferring expensive investments on large size plants, and on transmission and distribution system [20, 21]; (iv) reducing losses in the distribution system [21]; (v) providing network support or ancillary services [21]; (vi) promoting the use of alternative technologies and renewable sources especially in smart grids [18, 20, 22-24].

Similarly, FCs can have a large potential in the automotive industry [25-28] allowing to cut down the environmental impact of the mobility sector [25] and to overcome few of the major issues related to electric vehicles [28].

In the European Union (EU), residential and commercial buildings are responsible for $40 \%$ of the energy demand and for $36 \%$ of the carbon dioxide emissions [29]. In the United States (US) buildings utilized $41 \%$ of the primary energy consumed in 2010 [30, 31], 54\% of which only for the residential sector [31]. The International Energy Agency (IEA) estimates that CHP systems together with district heating and cooling could save $950 \mathrm{Mton} /$ year of carbon dioxide emissions by 2030 [32]. Thereafter, FC based CHP plants could significantly contribute 
to reduce the depletion of fossil energy sources and the global environmental footprint.

\begin{tabular}{lllll}
\hline \hline Model & CHP & $\begin{array}{l}\text { Cost } \\
{[\mathrm{k} €[}\end{array}$ & $\begin{array}{l}\text { Power } \\
{[\mathrm{kW}]}\end{array}$ & $\begin{array}{l}\text { Electrical } \\
\text { Efficiency }\end{array}$ \\
\hline Ballard ClearGEN [33] & Yes & NA & 500 & $40 \%$ \\
Ballard ElectraGen [34] & No & $17-50$ & $1.7-5$ & $40 \%$ \\
Baxi Gamma Premio [35] & Yes & NA & 1 & $34 \%$ \\
$\begin{array}{l}\text { Doosan FC Purocell } 5 \\
\text { [36] }\end{array}$ & Yes & NA & 440 & $43 \%$ \\
Elcore 2400 [35, 37] & Yes & 9 & 0.3 & $33 \%$ \\
Panasonic [35, 38] & Yes & $20-30$ & 0.75 & $37 \%-40 \%$ \\
Inhouse 5000+ [39] & Yes & NA & $1.5-5$ & $34 \%$ \\
Toshiba [35] & Yes & $20-30$ & 0.7 & $35 \%$ \\
Tropical NG-5 [40] & NO & NA & 5 & NA \\
Viessmann [35, 41] & Yes & 36 & 0.75 & $39 \%$ \\
Eneos [38] & Yes & $24.5-$ & 0.7 & NA \\
\hline \hline
\end{tabular}

Table 1: Examples of PEM Fuel cell energy systems available in the market or in a pre-commercial stage in the power range $0-500 \mathrm{~kW}$.

In the last two decades, different fuel cell technologies have been developed and entered the market of distributed CHP systems. Polymer electrolyte membrane (PEM) fuel cells are the most mature FC technology. At the end of 2012, PEM fuel cells, represented almost the $88 \%$ of the total fuel cell market [8]. Table 1 surveys the PEM based energy systems available on the market or in a pre-commercial stage with a nominal power below $500 \mathrm{~kW}$ [33-41]. Apparently, no commercial systems are available in the power range $[50 \mathrm{~kW}, 100 \mathrm{~kW}]$. The large investment cost is the main obstacle that hinders the market spreading of such a technology. In fact, actual costs reported in Table 1 are much larger compared to the targets set by the Fuel Cells and Hydrogen Joint Undertaking (FCH-JU) that are between $3500 € / \mathrm{kW}$ and $6500 € / \mathrm{kW}$ ] for energy systems in a power range between $5 \mathrm{~kW}$ and $400 \mathrm{~kW}$ [42]. Similarly, in [2] it is evidenced that PEM fuel cells are competitive with internal combustion engines as CHP prime movers for residential applications if the investment cost is below 3000 $€ / \mathrm{kW}$. Few relatively large demonstrative projects have been implemented leveraging on public financial support, such as the ENE-FARM project in Japan [43], the residential fuel cell demonstration programme in South Korea [44], the Callux residential project Germany [45], the FC-District Project operating in Spain, Greece and Poland [46], and the ene.Field project under the H2020 European programme [47].

The capital investment required for a PEM based CHP system is largely determined by the FC production volumes [38, 48-50]. In this scenario, the AutoRe project [51, 52] envisages the possibility of realizing a significant economy of scale by utilizing an automotive derivative PEM-FC as a prime mover for a micro-CHP system with a power of about $100 \mathrm{~kW}$. In fact, even a small series for an automotive industry could already represent a large market for power generation. For example, the sole Toyota plans to produce 40000 fuel cell commercial vehicles by 2020 and 400000 vehicles by 2030 [26, 27] over- selling the ENE-FARM project by an order of magnitude. The AutoRe plant is designed to be connected to the natural gas infrastructure and to produce electricity and heat for residential and commercial demands. The expected investment cost for mass production of such a plant is $2000 € / \mathrm{kW}$.

In this paper we perform a thorough techno-economic analysis of the $100 \mathrm{~kW}$ CHP plant that is being developed within the AutoRe project [52] under different energy management scenario. In particular we vary the energy demand by combining 5 different building typologies (an office building, an hotel, a clinic, an apartment district, and a supermarket) and 5 climatic conditions. Moreover, we dissect the impact of the surrounding energy system by considering the different electricity and natural gas costs and primary energy factors (PEF) relative to the American and European energy markets. For each scenario the plant control strategy is determined utilizing an optimization methodology developed by the authors [53-55]. We consider two different management policies: cost minimization and primary energy consumption minimization. The pay back period (PBP) is taken as an indicator of the economic feasibility of the plant. Its impact on the surrounding energy system is evaluated through the relative cost saving and the relative reduction of the primary energy consumption (PEC).

Such an analysis is performed with the twofold objective of assessing the effective performance of PEM based CHP plants under realistic scenarios and of disseminating the applicability of control strategy optimization optimization for different actors of the energy sector. First, the results will identify the technical (i.e. building type), environmental (i.e. climate), and economical (i.e. energy tariffs) conditions that promote the utilization of the proposed technology. The investment analysis, performed utilizing realistic input data and for a variety of different scenarios gives relevant information to the technology developers to determine the potential markets for PEM based CHP plants, thus assessing the effectiveness of the investments in such a technology. The comparison between the different optimization criteria could also help policy makers to identify the energy tariffs, supporting mechanisms, and policies that promote the efficient exploitation of advanced systems. Finally, results will demonstrate that design performance are not sufficient to evaluate an energy conversion technology. At the same time we propose an evaluation methodology based on the control strategy optimization that allow dissecting the behavior of complex power plant and facilitates the evaluation of the performance. The profitability of the plant or its energy and environmental advantages ere directly estimated as results of the optimization methodology, rather than relying on concepts such as the levelized cost of electricity or the CAPEX and OPEX.

The paper is organized as follows. The CHP system is briefly described in section 2 . In section 3 we define the methodology utilized to determine the optimal operating strategy and to perform the techno-economic analysis. The results are presented and discussed in section 5. Finally, conclusions are drawn in section 6 . 


\section{The automotive derivative PEM based CHP plant}

The prime mover of the CHP plant in study is a $100 \mathrm{~kW}$ PEM fuel cell whose schematic representation is given in Figure 1 . The electricity is generated within the FC by the catalytic oxidation of pure hydrogen. The FC operates at a temperature of $80^{\circ} \mathrm{C}$ and low grade thermal energy can be generated from the waste heat. Specifically, thermal energy is recovered both form the FC flue gases through a water cooled heat exchanger and from its cooling circuits (see Figure 1). The high temperature circuit removes heat from the bipolar plates and the low temperature one refrigerates the electronic components and other auxiliary systems. Despite the relatively low temperature $\left(65^{\circ} \mathrm{C}\right.$ for the low temperature circuit and $80^{\circ} \mathrm{C}$ for the high temperature one), such thermal energy can be profitably utilized in civil and commercial applications for space heating and domestic hot water production. In fact, these applications require hot water at a temperature comprised between $45^{\circ} \mathrm{C}$ and $75^{\circ} \mathrm{C}$.

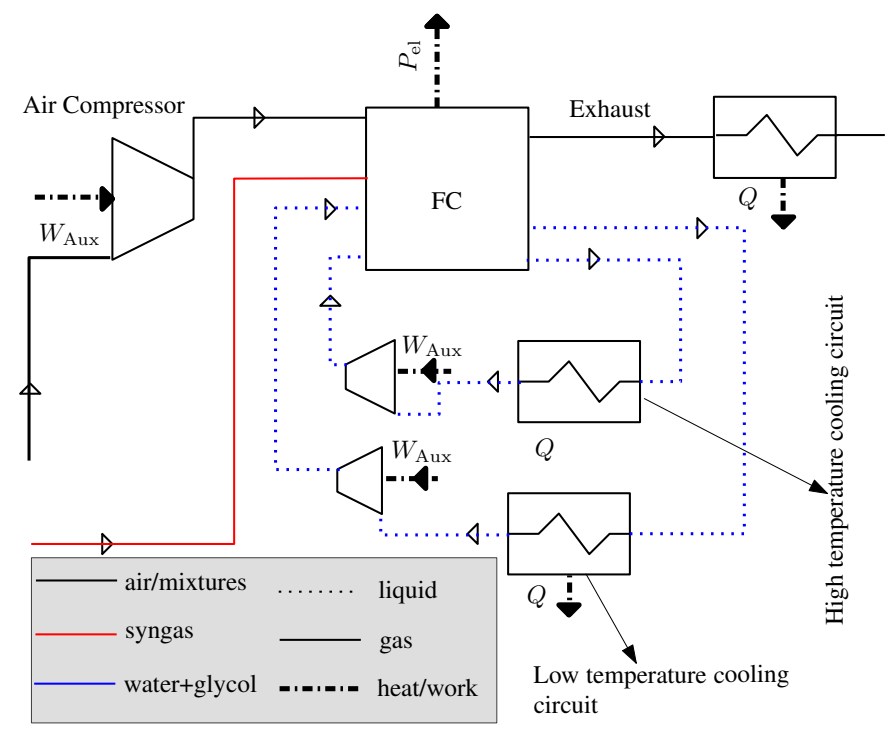

Figure 1: Schematic of the cogenerative PEM fuel cell.

The proposed energy system can be connected directly to the Natural Gas (NG) infrastructure thus requireing a dedicated fuel processor [56]. NG is converted into high purity hydrogen though the fuel processor represented in Figure 2. About $5 \%$ of the total amount of NG, together with tail gases from the Pressure Swing Adsorption (PSA) and oxidizing air, is directed to the catalytic burner, which provides the energy necessary for the endothermic steam reforming (SR). The catalytic burner is operated at ambient pressure and $790^{\circ} \mathrm{C}$. The air is pre-heated exchanging energy with the combustion flue gas, through the heat exchanger HE-2. Most of the NG is compressed to 12 bar and mixed with superheated steam at a temperature of $220^{\circ} \mathrm{C}$. Before entering the Steam Reformer (SR), the temperature of the NG-steam mixture is increased in the heat exchanger HE-3 absorbing the heat from the syngas exiting the SR. Then, a syngas primarily composed of $\mathrm{CO}$ and $\mathrm{H}_{2}$ is generated in the SR. The SR and the burner are integrated within the same component, following the concept of the Heat Integrated Wall Reactor
(HIWAR) [57, 58]. In such a reactor, the catalytic burned and the SR are separated by a conductive wall and thermal energy is transferred thanks to convection and conduction through the wall. HE-3 cools the syngas to $410^{\circ} \mathrm{C}$. Its temperature is further reduced to $320^{\circ} \mathrm{C}$ in the $\mathrm{HE}-4$ which is an air cooled heat exchanger utilized to facilitate the control of the fuel processor parameters. Finally, the $\mathrm{CO}$ concentration is reduced in a water gas shift reactor (WGSR). The thermal energy of the syngas at the WGSR outlet is transferred to the water necessary for the $\mathrm{SR}$ in the heat exchanger HE-5. The syngas temperature at the HE-5 outlet is $118^{\circ} \mathrm{C}$, and is further reduced to $5^{\circ} \mathrm{C}$ through the heat exchangers HE-6 and HE-7. Syngas is finally purified through a PSA. Impurities are adsorbed at high pressure and then are rejected reducing the system pressure (pressure swing). Most of the $\mathrm{H}_{2}$ contained in the syngas ( $75 \%$ to $80 \%$ ) is separated and sent to the FC. The remaining part of the hydrogen together with $\mathrm{CO}, \mathrm{CO}_{2}$, water and other impurities is redirected to the catalytic burner. Liquid water is compressed to 12 bar through a dedicated pump, pre-heated and partially vaporized in HE-5. Vaporization and superheating are completed in HE1 , where the steam is heated by the hot burner exhaust gas. The ratio between the water and NG mass flow rates is fixed to 3.73. Under design conditions the reformer delivers pure hydrogen at a pressure of 11 bar and at a temperature of about $5^{\circ} \mathrm{C}$.

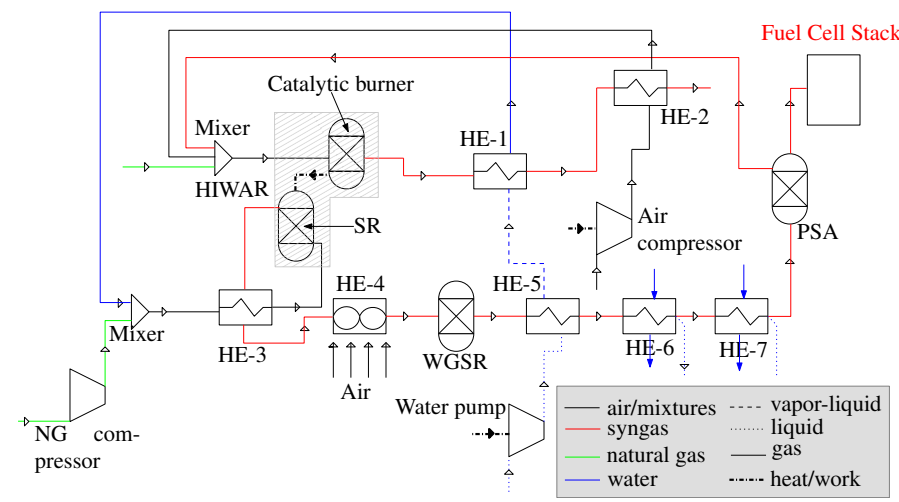

Figure 2: Schematic of the prime mover including the fuel processor and the FC. Note that the the catalytic burner and the SR are integrated in the same component named HIWAR.

The performance of this energy system has been estimated in [59] through a dedicated thermochemical model developed utilizing the AspenPlus ${ }^{\circledR}$ [60] modeling environment. In particular, the electrical efficiency is defined as

$$
\eta_{\mathrm{el}}=\frac{P_{\mathrm{el}}-W_{\mathrm{aux}}}{\dot{m}_{\mathrm{NG}} \mathrm{LVV}_{\mathrm{NG}}},
$$

where $P_{\mathrm{el}}$ is the gross electrical power produced by the FC, $\dot{m}_{\mathrm{NG}}$ is the NG mass flow and $\mathrm{LHV}_{\mathrm{NG}}$ is its lower heating value. Moreover, $W_{\text {aux }}$ is the electrical consumption of the auxiliaries including the natural gas and the air compressors, the water pumps, all the control systems. Similarly, the thermal efficiency is estimated as

$$
\eta_{\mathrm{th}}=\frac{Q}{\dot{m}_{\mathrm{NG}} \mathrm{LHV}_{\mathrm{NG}}},
$$


being $Q$ the thermal power output. Figure 3 reports the efficiency of the relevant subsystems of the plant as functions of their set-point, which is defined as:

$$
\mathcal{S}=\frac{P_{\text {output }}}{\max \left(P_{\text {output }}\right)},
$$

where, $P_{\text {output }}$ is the effective power output of the considered energy converter. (a) Fuel cell

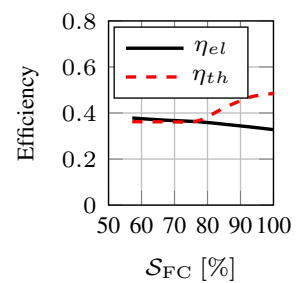

(b) Boiler

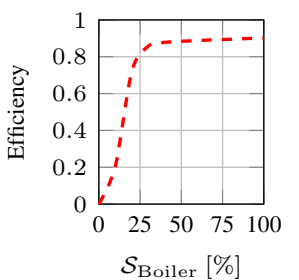

(c) Mechanical chiller

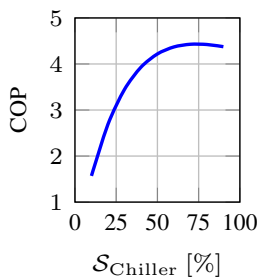

Figure 3: Efficiencies of the relevant components of the CHP plant as functions of set-point of each component: (a) Fuel cell; (b) Boiler; (c) Mechanical chiller.

Specifically, the electrical and thermal efficiency of the cogenerative FC are reported in Figure 3(a) as functions of the FC set point. The minimum FC load is $50 \%$ that corresponds to $\dot{m}_{\mathrm{NG}}=6.2 \mathrm{~kg} / \mathrm{h}$, below which the fuel processor cannot be operated. The thermal energy removed from the bipolar plates of the FC sharply increases for FC load higher than $75 \%$ presumably due to the increased impact of Ohmic losses at higher current density.

A natural gas burner and a mechanical chiller are also included in the energy system, as evidenced in Figure 4. Their efficiencies are retrieved from literature [61] and reported in Figure 3(b) and in Figure 3(c) as functions of the set-point. The size of the boiler and of the chiller in each case study are defined to satisfy the peak energy demand. Considering that such a peak demand is of the same order of magnitude, we assumed the same efficiencies of the boiler and of the chiller for all the considered cases.

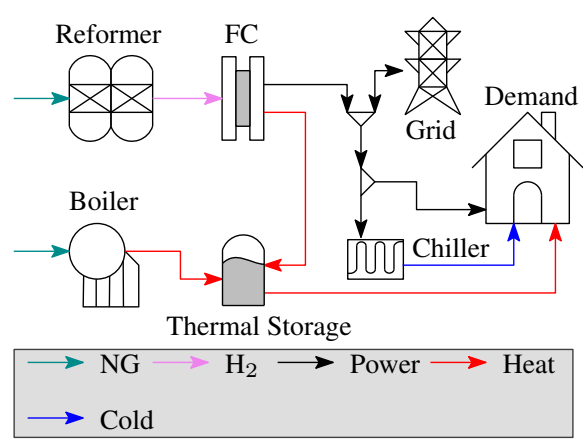

Figure 4: Schematic of the CHP plant in study including all the relevant components and connections.

Finally, a thermal storage is included in the CHP plant to increase its flexibility, releasing the plant from strictly following the heat demand. Following the results in [55], the capacity of the thermal storage is determined to satisfy the peak demand for three hours. For the thermal storage, a $90 \%$ round trip efficiency, defined as the ratio between the energy obtained from the storage discharge and the one spent to charge it, is assumed $[55,62]$.

\section{Methodology}

\subsection{Determination of the control strategy}

The operating efficiency of any power plant is largely determined by its control strategy, as highlighted, for instance, in $[12,53,54,61,63-67]$. Thereafter, we compare the performances of the different configurations assuming two possible smart management policies: cost and Primary Energy Consumption (PEC) minimization. Both control strategies are determined through the optimization methodology introduced in [53], and further developed in [55] and [54]. Such a methodology minimizes a prescribed objective function on a daily basis accounting for: (i) the design performances of all the subsystems; (ii) the derating of the performances at part load; (iii) the effects of environmental conditions; (iv) energy demand and costs as functions of time; (v) maintenance, and cold start costs; (vi) constraints related to the dynamic behavior of the equipment, such as the minimum time interval between two consecutive starts or shutdowns. All the energy converters are modeled as black-boxes, through their efficiency curves as functions of the set-point and the environmental conditions.

The prescribed objective function for cost minimization is:

$$
\begin{array}{r}
G_{\text {Cost }}=\sum_{h=1}^{24} C_{f}(h, s(h))+C_{m}(h, s(h))+ \\
+C_{s}(h, s(h))-R(h, s(h)),
\end{array}
$$

being $h$ the time interval, $C_{f}$ the cost of fuel, $C_{m}$ the maintenance cost, $C_{s}$ the cold-start cost, and $R$ the revenue/cost yielding from the electricity exchanged with the grid. Costs are functions of the time interval and the plant state (i.e. the set-point of the subsystems) $s(h)$.

PEC minimization is obtained through the following objective function

$$
G_{\mathrm{PEC}}=\sum_{h=1}^{24} E_{f}(h, s(h)) \mathrm{PEF}_{f}+E_{\text {grid }} \mathrm{PEF}_{\text {grid }},
$$

where $E_{f}$ is the energy content of the fuel, $\mathrm{PEF}_{f}$ is the primary energy factor of the fuel [68], $E_{\text {grid }}$ is the electricity exchanged with the grid, and $\mathrm{PEF}_{\text {grid }}$ is the primary energy factor of electricity [68].

Equations, (4) and (5) are discretized with respect to the plant state and in time, and the problem is represented as a weighted and oriented graph. The optimal control strategy is determined by seeking for the shortest path across the graph through dynamic programming [53-55, 69-71].

\subsection{Techno-Economic analysis}

To perform the techno-economic analysis of the CHP plant we first determine the optimal control strategy for a limited 
number of energy demand and climatic conditions $(N)$ across the year. Each load condition can be considered representative of a number $\left(N_{i}\right)$ of days. Thereafter, the generic yearly quantity $\Psi$ (e.g the cost, the PEC, or the utilization factor) can be calculated as

$$
\Psi=\sum_{i=1}^{N}\left(N_{i} \psi_{i}\right),
$$

being $\psi_{i}$ the relevant daily quantity.

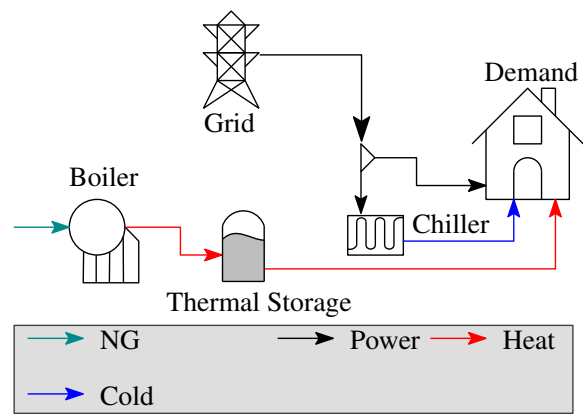

Figure 5: Schematic of the reference plant

The yearly results of the CHP plant in study are compared to the reference scenario, represented in Figure 5, where the energy demand is satisfied through a conventional plant that acquires electricity from the grid, produces thermal energy through a NG boiler, and cooling energy through a mechanical chiller. To estimate the economical feasibility of the plant we use the Pay Back Period (PBP) calculated through the following relationship:

$$
\mathrm{PBP}=\frac{I}{C_{\mathrm{ref}}-C} .
$$

In eq. (7) $I$ is the investment cost, $C_{\text {ref }}$ is the yearly energy cost of the reference scenario, and $C$ is the energy cost obtained utilizing the CHP plant. According to the estimation of the Department of Energy (DOE) of the United States of America [48], and to the objective of the AutoRe project, we assumed that $I=2000 € / \mathrm{kW}$. Such a cost includes the cogenerative FC and the fuel processor. The boiler and the chiller do not contribute to $I$ because they are already present in the reference plant. Therefore $I$ stands for the differential investment cost between the CHP plant and the reference plant.

\section{Case studies}

\subsection{Buildings selection}

The hourly electricity, heat, and cooling energy demands are available in the "commercial reference buildings" database [73] of the US Department of Energy (DOE) for 16 commercial reference buildings and for more than 1000 locations (i.e. different climatic conditions) within the US.

According to the International Energy Agency (IEA) 6 different climatic zones based on heating and cooling requirements can be considered representative of the whole world [72].

\begin{tabular}{l|cccl}
\hline \hline & HDD ${ }^{\circ} \mathrm{C}$ & CDD $^{\circ} \mathrm{C}$ & Europe & USA \\
\hline Cold & $\geq 2000$ & $\leq 500$ & Warsaw & Helena \\
Heating & $\geq 2000$ & {$[500,1000]$} & Milan & Baltimore \\
Based & $\leq 2000$ & $\leq 1000$ & Malga & $\begin{array}{l}\text { San Fran- } \\
\text { cisco }\end{array}$ \\
Moderate & $\leq 1000$ & Athens & Las Vegas \\
Cooling & {$[1000,2000]$} & $\geq 1000$ & Larnaca & Phoenix \\
Based & $\leq 1000$ & $\geq 1000$ & & \\
Hot & & & & \\
\hline \hline
\end{tabular}

Table 2: Heating and cooling degrees days and representative cities for each IEA climatic zone [72].

1. Cold climate: winter is cold and summer temperatures never or only rarely reach a level above comfort level $\left(22^{\circ} \mathrm{C}-25^{\circ} \mathrm{C}\right)$. This is the case for large parts of Russia, Scandinavia and Canada.

2. Heating based climate: the need for heating in winter is large, but summer temperatures can reach a level where cooling becomes an option at least for comfort. This is the case for Central and North of Europe, most of Canada and central US.

3. Combined climate: heating is necessary in winter as well as cooling in summer. This applies to Moscow and central parts of Russia, Shanghai region and other parts of in China.

4. Moderate climate: both summer and winter are mild and the need for heating and cooling is quite limited. Such a climate condition applies to Portugal and central parts of California, as examples.

5. Cooling based climate: summer is hot with a need for cooling in the summer and a limited need for heating in the winter. Greece, part of Italy, southern California, Australia are examples of such a climate condition.

6. Hot climate: summer is hot and winter is warm with winter temperatures never below the comfort level $\left(16^{\circ} \mathrm{C}\right.$ $\left.18^{\circ} \mathrm{C}\right)$. Such a climate is present in Florida, northern Australia, and Central Africa.

Each climatic zone is characterized by the heating degrees days (HDD) and cooling degrees days (CDD) per year, as reported in Table 2. The reference temperature is $18^{\circ} \mathrm{C}$ for both CDD and HDD. We comment that we discarded the combined climate, because it is not representative of Europe nor of Unites States.

Five buildings among the 16 available in [73] have an average electrical demand in the range $[60-200] \mathrm{kW}$ and are selected to evaluate the performances of the CHP plant under investigation. Specifically, we considered a medium office, an apartment district, a clinic, a small hotel, and a supermarket, as feasible applications of the proposed power plant. For the residential case, considering the low attitude to capital intensive investments of the families, we considered a cluster of 4 buildings. The resulting peak electrical demand is about $180 \mathrm{~kW}$ that correspond to the power needed by about $40-60$ families ( $10-15$ apartments per building) sharing the $200 \mathrm{k} €$ initial investment. The peak power demand for these buildings is in the 
range $[120-320] \mathrm{kW}$. Peak and average electrical, thermal, and cooling energy demands are represented in Figures 6, 7, and 8, respectively, for all the combinations of building and climatic zone. We note that the electricity load is only marginally influenced by the location of the plant. On the contrary, the climatic zone significantly impacts the heat and cooling demand.

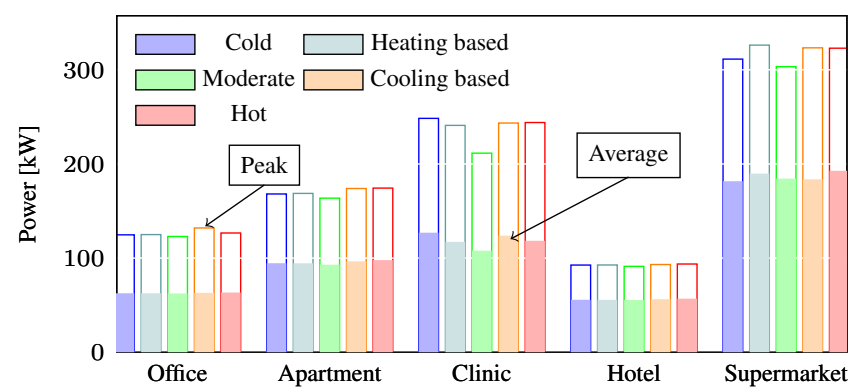

Figure 6: Average and peak electricity demand for all the combinations of climatic condition and building energy demands.

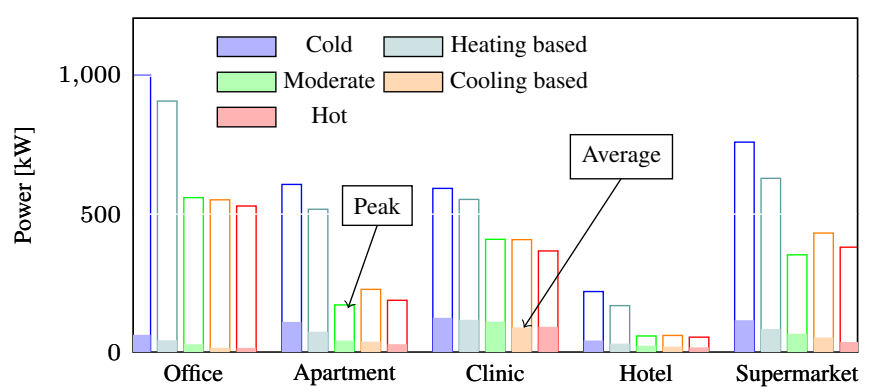

Figure 7: Average and peak heat demand for all the combinations of climatic condition and building energy demands.

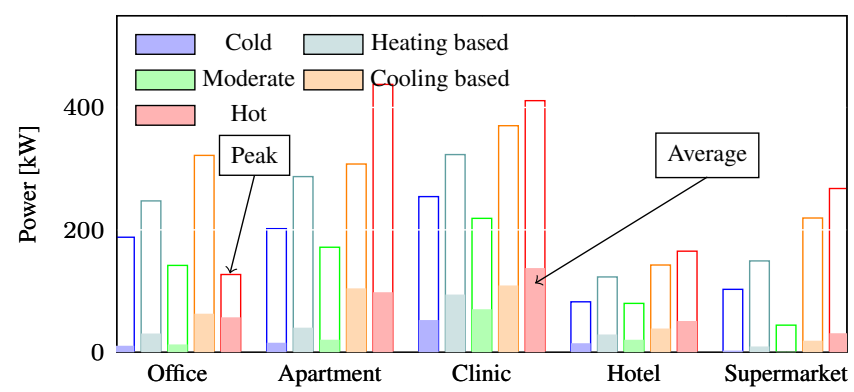

Figure 8: Average and peak cooling demand for all the combinations of climatic condition and building energy demands.

To further analyze the energy demands we calculate, through eq. (8), the number of equivalent working hours of the FC necessary to satisfy the total demand of electricity for one year .

$$
\tau=\frac{E_{\mathrm{el}}+E_{\mathrm{ch}} / \overline{\mathrm{COP}}}{P_{\mathrm{el}}} .
$$

The total electrical demand is calculated summing the pure electricity demand, $E_{\mathrm{el}}$, to the electricity required by the chillers, which is given by $E_{\mathrm{ch}} / \overline{\mathrm{COP}}$, being $E_{\mathrm{ch}}$ the cooling energy demand, and $\overline{\mathrm{COP}}$ the average COP of the chillers. According to the data reported in Figure 3(c) we assume that $\overline{\mathrm{COP}}=3$.
The ratio between the required thermal and electrical energy (HoP) helps studying the impact of the CHP system on the different scenarios. In fact, the HoP is an indicator of the capability of the energy user to effectively utilize both the power and the heat produced by the energy system. Such a parameter is calculated as

$$
\mathrm{HoP}=\frac{E_{\mathrm{th}}}{E_{\mathrm{el}}+E_{\mathrm{ch}} / \overline{\mathrm{COP}}} .
$$

where $E_{\mathrm{th}}$ is the heat required by the building in one year.

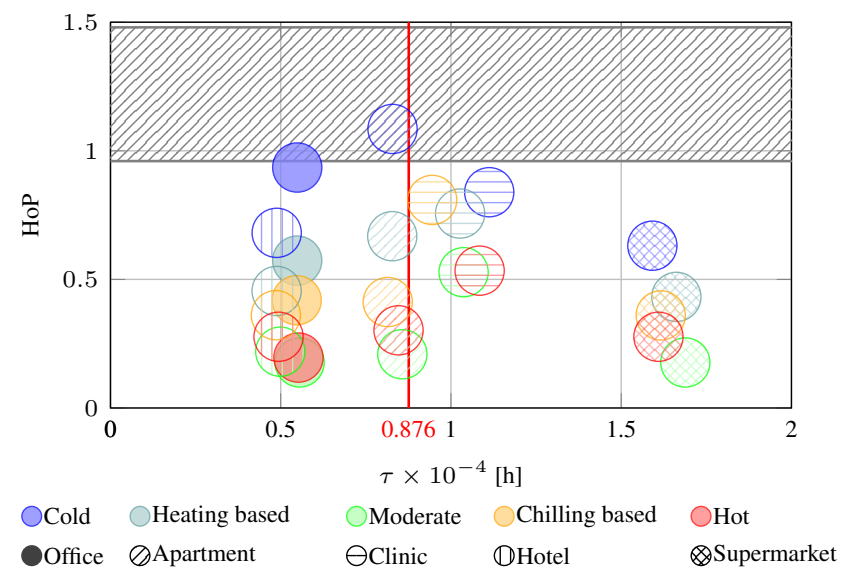

Figure 9: Heat to power ratio and fuel cell equivalent working hours necessary to satisfy yearly energy demand for all the combinations of building and climate. The shaded area is the heat to power ratio of the FC.

Figure 9 classifies the considered energy demands according to $\tau$ and HoP. The shaded region represents the heat to power ratio of the FC. Such a ratio varies as a function of the FC set-point, considering that both its electrical and thermal efficiencies depend on it. From Figure 9 note that the HoP is below the shaded region for the majority of the considered cases, meaning that the electrical tracking policy for the CHP would yield a thermal energy overproduction. On the contrary, thermal tracking would require to import a part of the electricity from the grid. The apartment district and the office building in cold climate are exceptions, being characterized by a larger HoP. As expected, the HoP is strongly influenced by the climate that largely determines the thermal demand, while having a minor impact on electrical demand. Thereafter, the buildings approximately cluster along vertical lines with the abscissa varying as a function of the climatic condition. The impact of the climate on the HoP is lower for the clinic mainly because of a significant utilization of heat for usages other than space heating. In fact, for the clinic, HoP $>0.5$ also for moderate to hot climates, differently from the other buildings. The office building and the hotel are characterized by $\tau \simeq 5000 \mathrm{~h}$, being the FC capable of producing more electricity than the required yearly quantity. On the contrary, some electricity must be acquired from the grid for the supermarket and the clinic that are characterized by $\tau>8760 \mathrm{~h}$. Finally, $\tau \simeq 8760 \mathrm{~h}$ for the apartment district where the FC is designed to fulfill approximately the average electrical demand. 


\subsection{Hourly energy demand of the sample days}

The optimization methodology that has been utilized to study the behavior of the AutoRe power plant in a real energy management scenario requires the hourly energy demand to determine the optimal control strategy [53]. Utilizing the hourly energy demand for the whole year (8760 hours) provided in [73] would require an impractical computational effort. Thereafter 9 average working and 9 average non-working days are constructed for each combination of building and climatic zone based on heat and cooling demand levels and are considered representative of the whole year.

Specifically, we calculate the following coefficients,

$$
\begin{aligned}
& K_{Q}=\operatorname{int}\left[\frac{1}{2} \frac{\max \left(\overline{Q_{\text {day }}}\right)}{\overline{Q_{\text {year }}}}\right], \\
& K_{C}=\operatorname{int}\left[\frac{1}{2} \frac{\max \left(\overline{C_{\text {day }}}\right)}{\overline{C_{\text {year }}}}\right],
\end{aligned}
$$

where, $\overline{Q_{\text {day }}}$ and $\overline{C_{\text {day }}}$ are the daily averages of heat and cooling demand, and $\overline{Q_{\text {year }}}$ and $\overline{C_{\text {year }}}$ represent their yearly averages. Then, each day of the year is categorized by comparing the ratios reported in eq. 11 to the reference values reported in Table 3.

$$
\begin{aligned}
& \alpha_{i}=\frac{1}{K_{Q}} \frac{\overline{Q_{\text {day }}}}{\overline{Q_{\mathrm{w} / \mathrm{h}}}}, \\
& \beta_{i}=\frac{1}{K_{C}} \frac{\overline{C_{\text {day }}}}{\overline{C_{\mathrm{w} / \mathrm{h}}}},
\end{aligned}
$$

being $\overline{Q_{\mathrm{w} / \mathrm{h}}}$ and $\overline{C_{\mathrm{w} / \mathrm{h}}}$ the yearly averages calculated considering either only working days (if $\alpha_{i}$ refers to a working day) or only holidays (if $\alpha_{i}$ refers to a non working day). Finally, the load profiles of all the 18 sample days are calculated as the ensemble average of the energy demands of the days pertaining to each category.

In the following, the working days are indicated with the abbreviation $w_{i}$ and the non-working days (Sundays and Saturdays) are be abbreviated with $h_{i}$, with $i=1 \ldots 9$.

Figures 10 and 11 report an example of the obtained load profile. Specifically, the case of the apartment district in the heating based climate is depicted. The standard deviation is also represented for each demand time series, evidencing the fidelity of the procedure described in this paragraph and of the values of $\alpha_{i}$ and $\beta_{i}$. In particular, the standard deviation for the electrical demand is very limited, being the power demand only marginally influenced by climatic conditions. On the contrary, external temperatures and light hours have a significant impact on the thermal and cooling energy demand that exhibit a slight larger standard deviation.

\subsection{Energy prices and primary energy factors}

The optimization procedure requires the prices of all the energy vectors in input to and output from the power plant. Electricity is the only energy output of the energy system since heat and cooling energy can only be utilize within the plant.
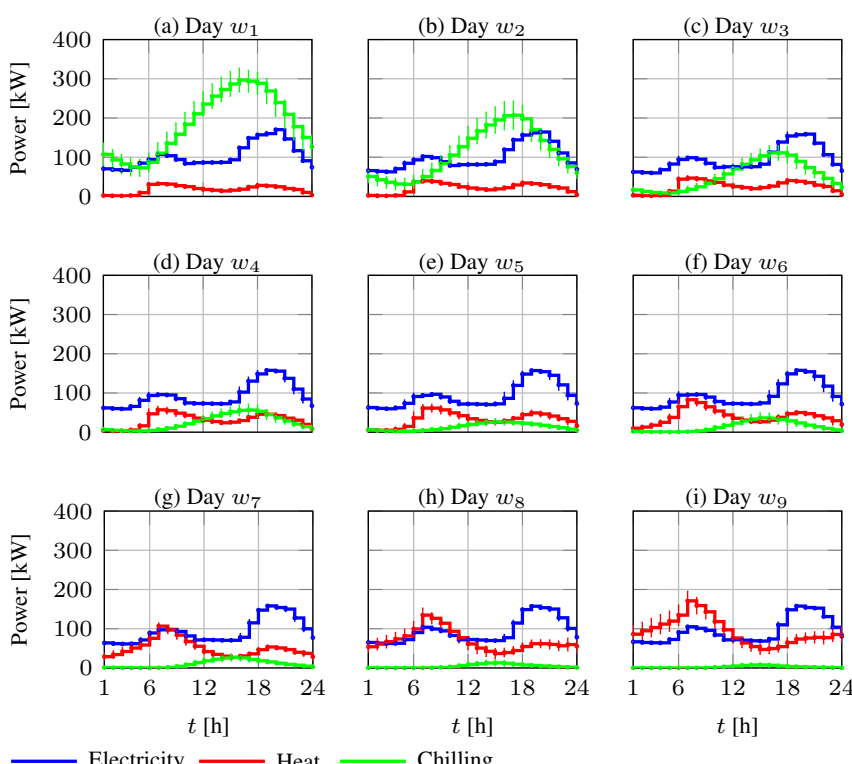

Figure 10: Hourly energy demand for the 9 sample working days for the Apartment case and cooling based climate.
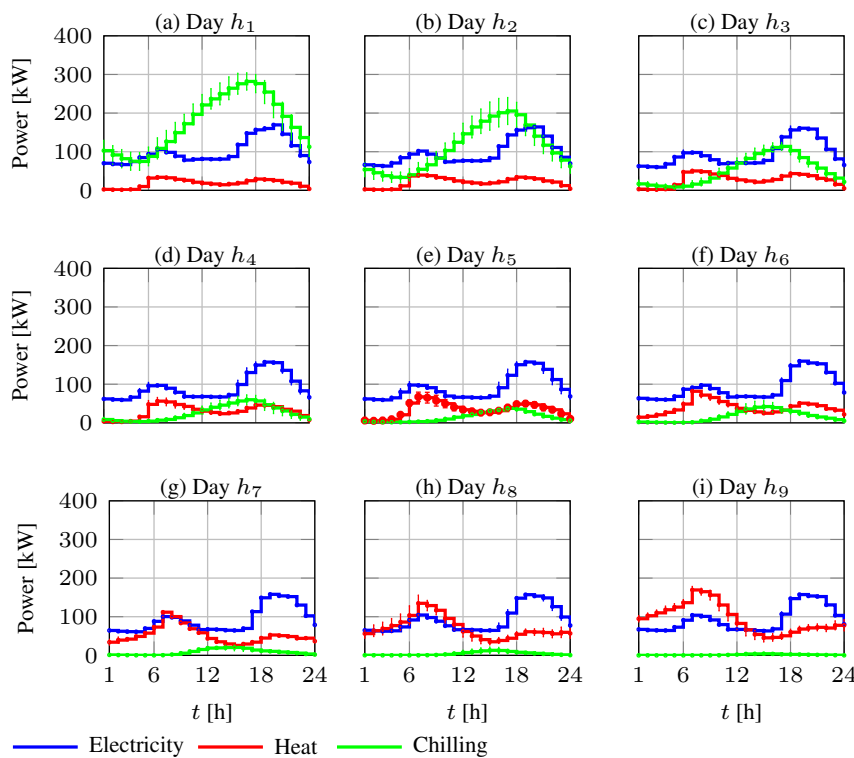

Figure 11: Hourly energy demand for the 9 sample non-working days for the Apartment case and cooling based climate.

Although the CHP system is connected to the electrical grid to increase the flexibility, any overproduction may be entered into the grid without remuneration. Such an assumption facilitates the generalization of the methodology and of the results to different countries. In fact, the remuneration of electricity produced by DG plants is subject to stringent national rules. Moreover, prices are strongly influenced by complex subsidizing mechanisms that vary on a national basis. Finally, we note that such an assumption is expected to underestimate the profitability of PEM based plants and is therefore cautionary with respect to the conclusions of the research..

The possible input energy sources are natural gas and elec- 


\begin{tabular}{cccccccccc}
\hline \hline & $i=1$ & $i=2$ & $i=3$ & $i=4$ & $i=5$ & $i=6$ & $i=7$ & $i=8$ & $i=9$ \\
\hline$\alpha_{i}$ & $\leq 0.125$ & $\leq 0.125$ & $\leq 0.125$ & $\leq 0.125$ & $\leq 0.125$ & {$[0.125,0.25)$} & {$[0.25,0.5)$} & {$[0.5,1)$} & $\geq 1$ \\
$\beta_{i}$ & $\geq 1$ & {$[0.5,1)$} & {$[0.25,0.5)$} & {$[0.125,0.25)$} & $\leq 0.125$ & $\leq 0.125$ & $\leq 0.125$ & $\leq 0.125$ & $\leq 0.125$ \\
\hline \hline
\end{tabular}

Table 3: Reference values for the coefficients $\alpha$ and $\beta$ utilized to categorize each day of the year. Note that "[" denotes that the extreme value is included and ")" that it is excluded.

\begin{tabular}{c|ll|ll}
\hline \hline & \multicolumn{2}{|c|}{ Electricity [c€/kWh] } & \multicolumn{2}{c}{ Natural gas [€/GJ] } \\
\hline & Residential & Commercial & Residential & Commercial \\
\hline USA & 12.99 & 11.02 & 8.58 & 6.54 \\
EU & 22.09 & 15.41 & 15.13 & 11.43 \\
\hline \hline
\end{tabular}

Table 4: Energy prices utilized for the different scenarios. Data from [74-76]

tricity. For completeness we considered two different energy markets: Europe and United States, whose prices are reported in Table 4. In both cases we assume that the natural gas and electricity unit cost are constant throughout the day and the year. All prices are inclusive of all taxes and levies. For Europe, electricity and natural gas prices are retrieved from the Eurostat database [74]. For United States, the electricity cost is obtained from [75], and the natural gas cost is retrieved from [76]. The residential prices are utilized only for the residential district cases, while the commercial prices apply to all the other buildings.

PEC minimization requires the primary energy factors of all the energy vectors entering the plant. The PEF of NG is 1.1 [68] for both th EU and US. In US, the PEF of electricity is 2.174 [77] while in US it is 3.140 [78, 79].

\section{Results and discussion}

The method described in section 3.1, determines the optimal set-point for each system component on a hourly basis (see e.g. $[53-55,80])$. A number of instantaneous and mean parameters, such as fuel and maintenance costs, efficiencies, fuel or primary energy consumption, utilization factors and many others can be retrieved as functions of the set-point [53-55, 80]. Here, we concentrate on the most relevant global parameters to analyze the effectiveness of the CHP plant in study for different scenarios. Figures 12 to 15 report the yearly total cost, PEC, and FC and boiler utilization factors, for all the combinations of building scenario, climatic condition, energy cost, and management policy (i.e. cost or PEC minimization). Therein, CHP production is also compared to the reference scenario, where electricity is acquired from the grid, heat is locally produced through a NG boiler, and cooling energy comes from a mechanical chiller.

In this analysis, by comparing cost and PEC minimization, we seek for the conditions that foster the coherence between economic savings and PEC reduction conditions, in terms of energy demand and unit energy costs. Such conditions might be considered the most positive for PEM based CHP plants. In fact, while the primary rationale for utilizing a cogeneration plant is economic [32, 81], primary energy saving and environmental protection are usually the drivers for choosing the FC technology [12, 82, 83].

Cogeneration consistently reduces the energy cost for all the considered cases irrespective to the hypothesized control strategy. Utilizing the economic optimization such a cost reduction is comprised between about $100 \mathrm{k} € /$ year (apartment in cold climate with European energy prices) and about $30 \mathrm{k} € /$ year (hotel in moderate climate with US energy prices). Similarly, PEC minimization yields an economic saving between $92 \mathrm{k} € /$ year (clinic in cold climate with European energy prices) and about $17 \mathrm{k} € /$ year (hotel in hot climate with EU energy prices). Note that such economic savings generally compare with the initial investment for the CHP system which is about $200 \mathrm{k} €$ having assumed a unit cost of $2 \mathrm{k} € / \mathrm{kW}$ (see section 2).

Another feature, common to all the scenarios, is that the CHP dramatically reduces the boiler utilization with respect to the reference case. Thereafter, the heat demand is effectively satisfied through cogeneration.

The utilization factor of the FC is generally larger than 50\%, thus evidencing that the prime mover is never underutilized, or, equivalently, that the FC size is correctly defined with respect to the energy demand. As partial exceptions, we observe that in the European scenario the PEC minimization yields utilizations lower than $50 \%$ for the office, the clinic, and the hotel in warm climates. For such cases the impact of the FC on the energy demand satisfaction is questionable and a smaller CHP plant could be considered a more viable solution.

\subsection{Effects of the energy demand: building and climate}

The building type and the climate determine the energy demand that, in turn, influences the total cost and the PEC for both the reference and the CHP plant. In this section we assess the effect of the energy demand on both the techno-economic feasibility of the PEM and on its impact on the energy system. The PBP is taken as an indicator of the techno-economic feasibility and the impact of the power plant on the building is determined by the relative cost and PEC reduction. All such quantities are synthetically reported in Figure 16, for the US scenario and economic optimization. We comment that we begin this analysis assuming the US unit energy prices and PEFs because the energy demand profiles were originally estimated for the US territory [73].

PBP is below 10 years for all the considered cases, and is between 4 and 5 years for all the building typologies, except for the hotel and the office in moderate climate. Therefore the investment is feasible in general, but the hotel should be considered a borderline case with a PBP comprised between 6 and 7 years. The PBP is only marginally influenced by the climatic condition, or equivalently by the HoP, despite colder climates are generally characterized by a lower PBP. If we compare the 
(a) Total energy cost

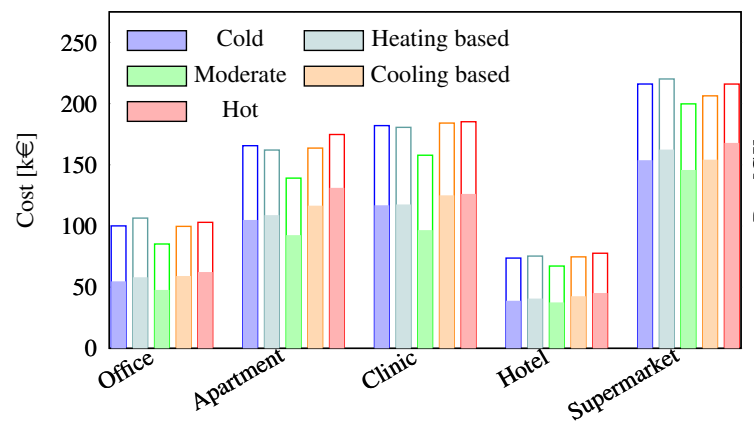

(c) PEMFC utilization factor

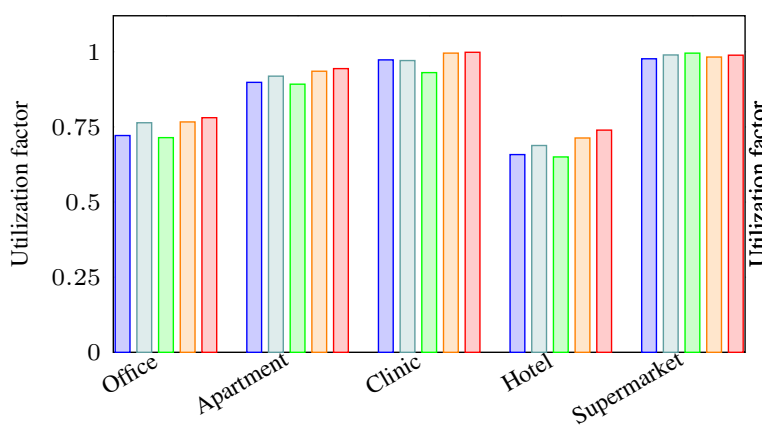

(b) PEC

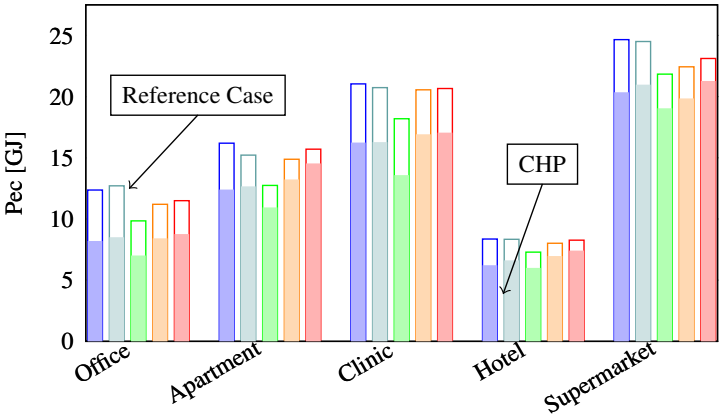

(d) Boiler utilization factor

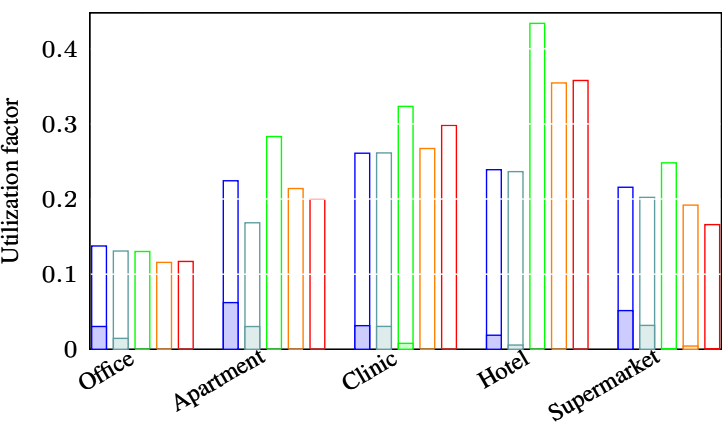

Figure 12: Global performances of the CHP power plant with the minimum cost strategy in the US scenario: (a) Total energy cost; (b) Primary energy consumption; (c) Utilization factor of the fuel cell; (d) Utilization factor of the boiler.

(a) Total energy cost

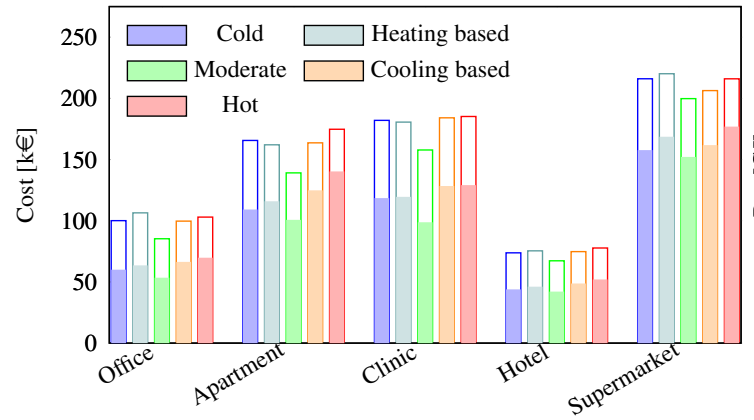

(c) PEMFC utilization factor

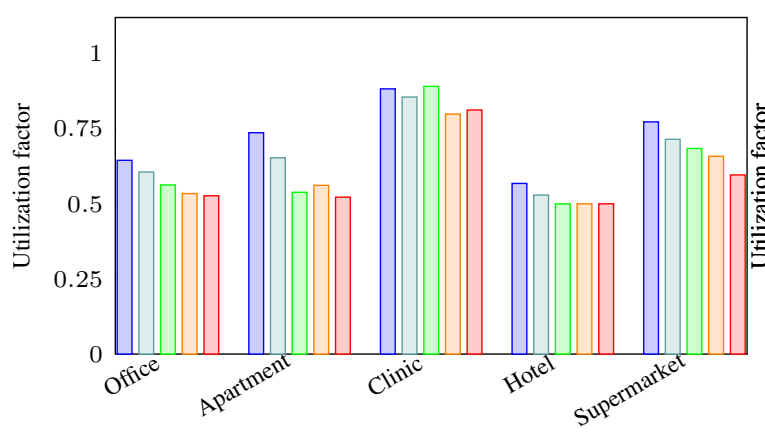

(b) PEC

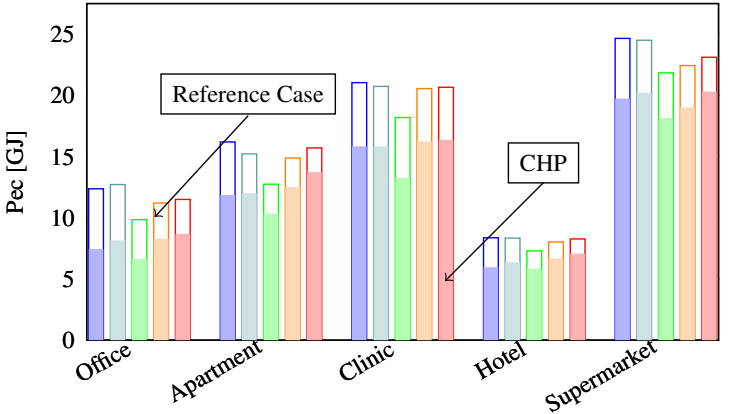

(d) Boiler utilization factor

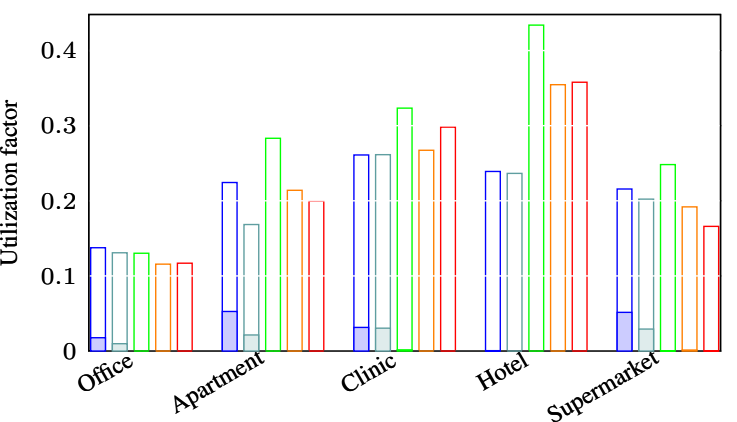

Figure 13: Global performances of the CHP power plant with the minimum PEC strategy in the US scenario: (a) Total energy cost; (b) Primary energy consumption; (c) Utilization factor of the fuel cell; (d) Utilization factor of the boiler. 
(a) Total energy cost

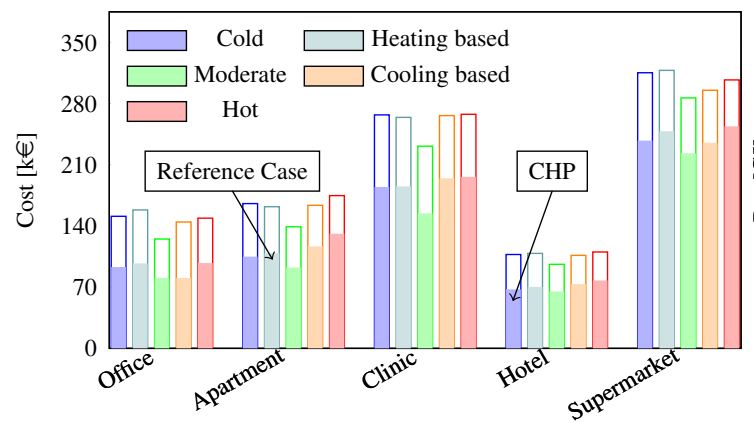

(c) PEMFC utilization factor

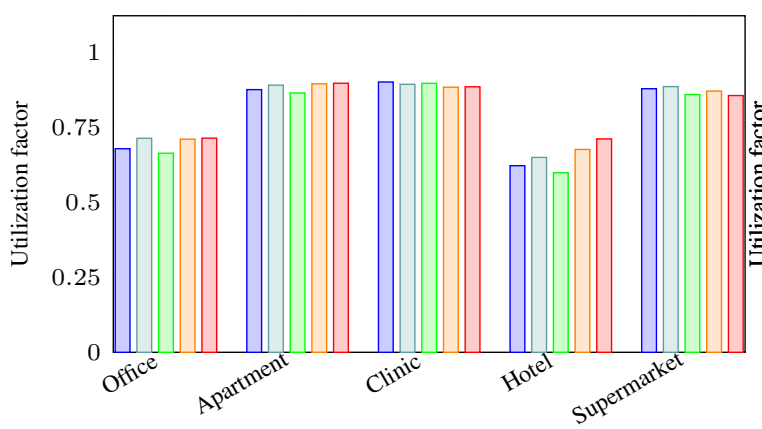

(b) PEC

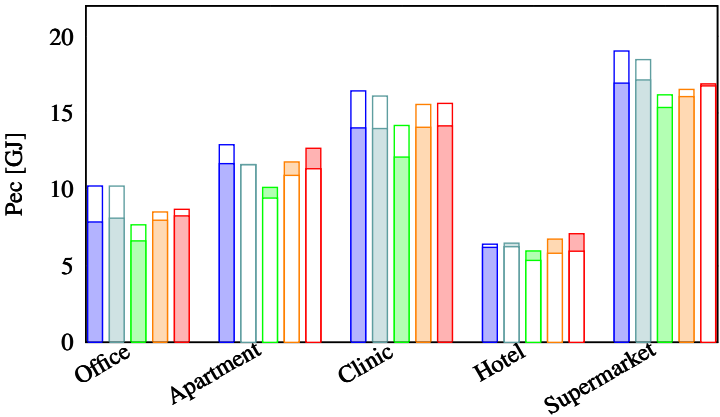

(d) Boiler utilization factor

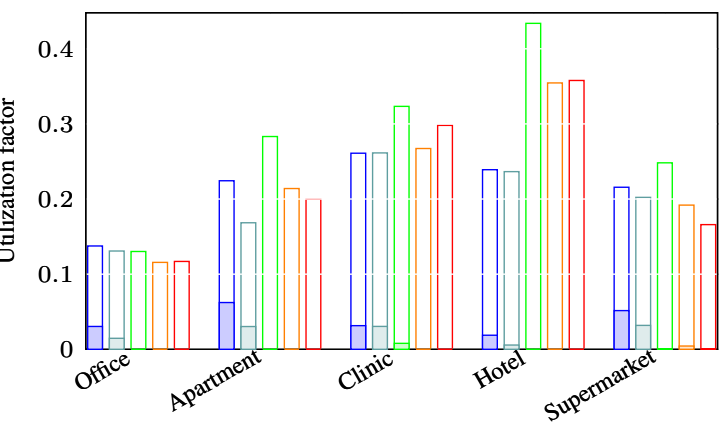

Figure 14: Global performances of the CHP power plant with the minimum cost strategy in the EU scenario: (a) Total energy cost; (b) Primary energy consumption; (c) Utilization factor of the fuel cell; (d) Utilization factor of the boiler.

(a) Total energy cost

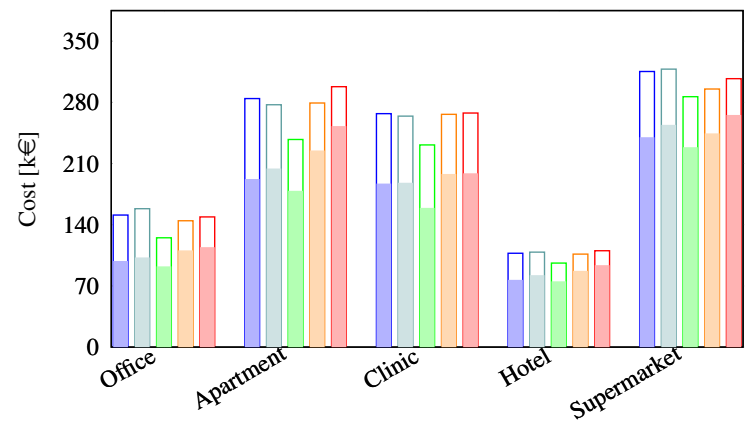

(c) PEMFC utilization factor

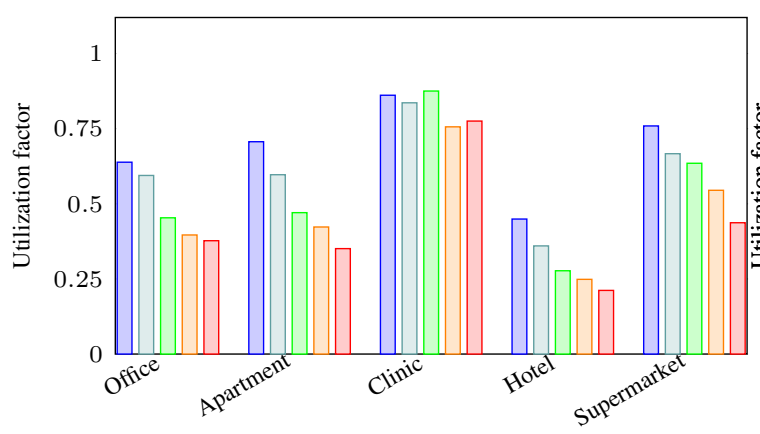

(b) PEC

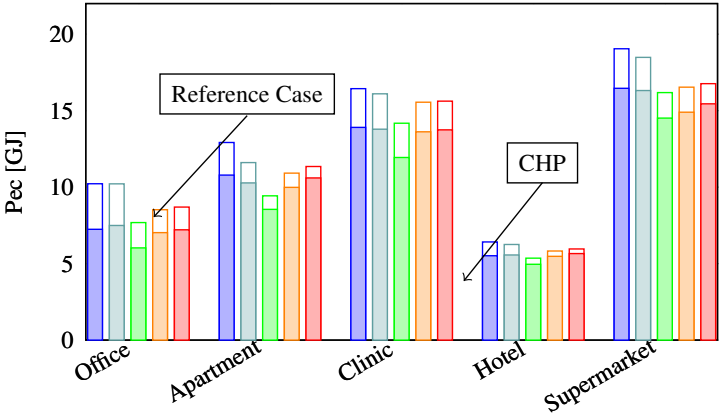

(d) Boiler utilization factor

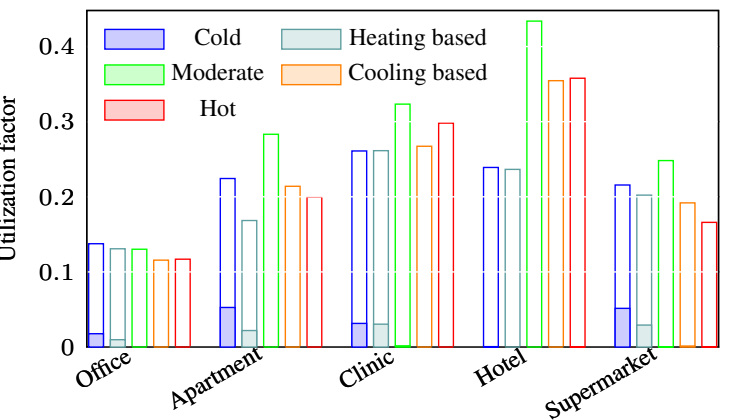

Figure 15: Global performances of the CHP power plant with the minimum PEC strategy in the EU scenario: (a) Total energy cost; (b) Primary energy consumption; (c) Utilization factor of the fuel cell; (d) Utilization factor of the boiler. 


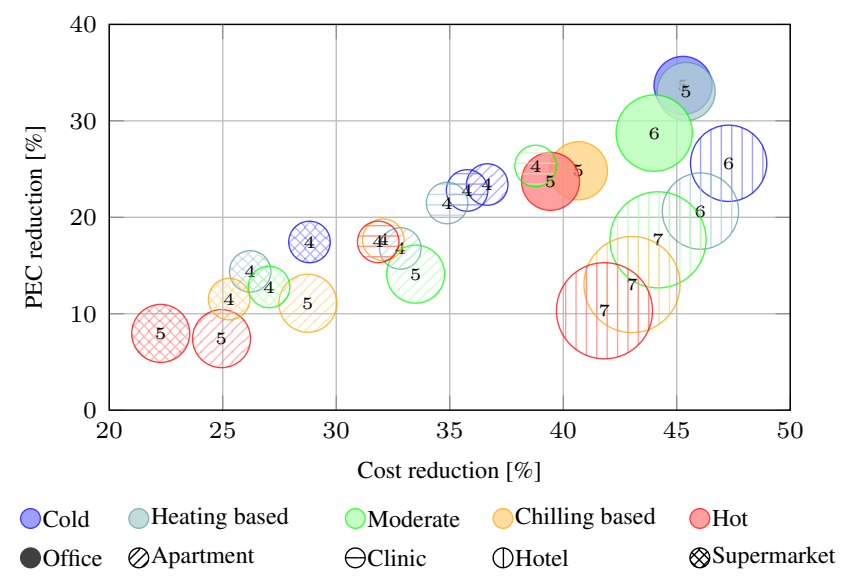

Figure 16: Comparison between the different scenarios for the minimum cost strategy and the US energy market: the area of the circles is proportional to the pay back period and the center of the circles defines relative cost and PEC reduction.

results of Figure 9 to those reported in Figure 12 and Figure 16 we note that $\tau$ clearly affects the FC utilization factor, which, in turn, determines the PBP. Specifically, the hotel has the lowest utilization factor, slightly below the office, and $\tau$ is close to $5000 \mathrm{~h}$ for both building typologies. The lowest PBP attains to the clinic ( 4 years and $\tau \simeq 10000 \mathrm{~h}$ ) and to the supermarket (4 to 5 years and $\tau \simeq 16000 \mathrm{~h}$ ), but the clinic is more favorable, in particular for warm climates, despite the lower energy demand. Note that $\tau$ is a property of the the energy demand, and not of the power plant. Specifically, $\tau>8760$ entails that the average electricity demand is higher than the power of the FC, as evidenced in eq 8 . Such a behavior can be explained by considering that the clinic has a larger HoP (between 0.5 and 1) compared to the supermarket (see Figure 9), that facilitates the utilization of the cogenerated heat. Moreover, we observe that increasing $\tau$ from $5000 \mathrm{~h}$ to $10000 \mathrm{~h}$ impacts the investment feasibility, reducing the PBP by about $30 \%$. However, a further increment in $\tau$ does not generate any reduction of the pay back time. In fact, Figure 12 evidences that the FC utilization already saturated to a value close to 1 for the clinic energy demand and cannot be further increased by increasing the energy demand. This explains why the cost reduction is roughly the same for the clinic and the supermarket, despite the the latter has a larger energy cost (see Figure 12).

The impact of the CHP plant on the energy system is significant for all the considered cases. In fact, the PEC reduction is in the range $[8 \%, 33 \%]$ and the relative cost reduction is comprised between $22 \%$ and $47 \%$. Notably, the PEC is reduced for all the considered cases even though we utilize the economic optimization to determine the CHP control strategy. The economic objective function is not directly influenced by the PEC (see eq. 4) and it was demonstrated in literature that maximizing the economic profitability does not generally imply a reduction of the PEC [54, 55]. The coherence between these two criteria largely relies on the ratio between electricity unit cost and PEF. Thereafter, the results reported in Figure 16 highlight that, in the US scenario, the energy cost is coherent with the efficiency of the national electricity production and distribution systems. The primary energy factor of the electricity produced by the $\mathrm{FC}, \mathrm{PEF}_{\mathrm{FC}}=\mathrm{PEF}_{\mathrm{NG}} / \eta_{\mathrm{el}}$, is comprised between 2.91, at low load, and 3.35, at full load, (see Figure 3 for the values of $\eta_{\mathrm{el}}$ ). On the other hand, $\mathrm{PEF}_{\text {grid }}=3.14$ for the US national grid. Therefore, in the US scenario, DG through the plant in study is more efficient compared to central generation, even for the sole electricity production (i.e. with no cogeneration) for FC set points lower that $85 \%$. For larger set points, the utilization of a minor part of the FC waste heat (about 10\%) is sufficient to increase the system efficiency above the electricity grid one.

Both the building type and the climate have an important impact on the cost and PEC relative variation. Varying the climatic condition, the scenarios relative to each building cluster along lines with a positive slope comprised between $55^{\circ}$ and $70^{\circ}$. In fact, moving from hot to colder climates generally improves the relative reduction of both cost and PEC. The values of the slope indicates that the climate conditions have a larger effect on the PEC rather than on the cost. On the contrary, the building type dominates the relative cost reduction, which is generally reduced increasing the HoP.

Summarizing, the clinic, that is characterized by $\tau \simeq 10000$ $\mathrm{h}$ and $0.53<\mathrm{HoP}<0.84$, can be considered the most favorable energy demand for all the climates. In fact, in this case, the utilization of the proposed CHP plant significantly reduces the PEC $([-17 \%,-23 \%])$ and the total energy cost $([-32 \%,-38 \%])$, and the $\mathrm{PBP}=4$ years.

\subsection{Effects of the control strategy: cost and PEC minimization}

Cost minimization does not imply that the energy consumption is optimized, in particular for grid connected power plants $[54,55,80]$. In fact, by comparing Figure 12(b) to Figure 13(b) we note that operating the proposed plant through the minimum PEC policy boosts its energy performance, for the US energy prices and PEFs. Specifically, the PEC variation can be incremented up to $70 \%$ with respect to the minimum cost control strategy. The apartment district exhibits the most relevant efficiency improvement with a variation of the PEC reduction in the range $[14 \%, 70 \%]$ updating the control strategy. On the contrary, the office building is the least affected energy demand, with a variation of the PEC reduction comprised between $3.5 \%$ and $18 \%$. The improvement of the energy efficiency is more relevant in hot climates, where the low HoP (see Figure 9) hinders the recovery of the the FC waste heat. If we compare the results of Figure 12(c) to those reported in Figure 13(c), we note that PEC minimization reduces the FC utilization factor with respect to economic optimization. With cost minimization the FC utilization is only marginally affected by the climate, as evidenced in Figure 12(c). On the other hand, through the minimum PEC policy, the climate moderately impacts the FC utilization (see Figure 13(c)). In particular, the FC utilization is larger for colder climates compared to the warmer ones. In fact, PEC minimization reduces the FC set point to increase its electrical efficiency, in particular when the HoP is low. In such cases, operating the FC at a high load, with a reduced heat recovery, could reduce the system efficiency below the grid level. 


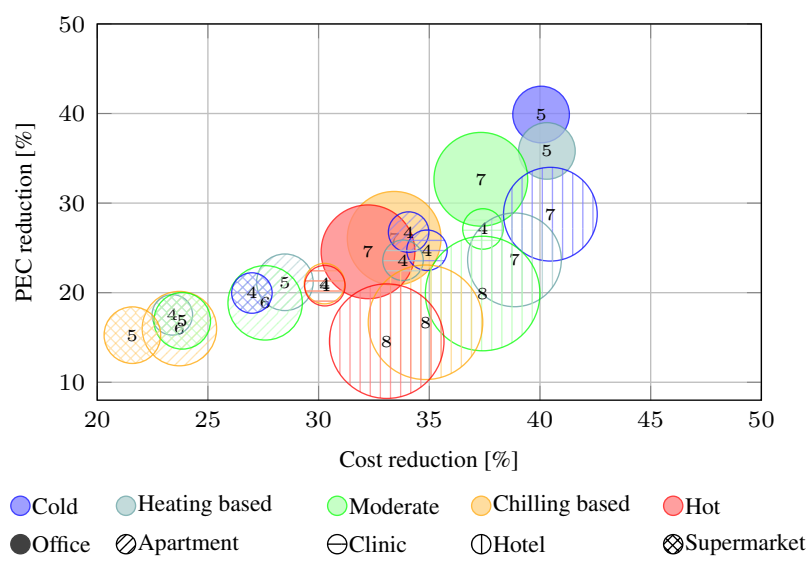

Figure 17: Comparison between the different scenarios for the minimum PEC strategy and the US energy market: the area of the circles is proportional to the pay back period and the center of the circles defines relative cost and PEC reduction.

Figure 17 systematically represents the PEC and cost reductions and the PBP obtained through the minimum PEC control strategy, evidencing that such a policy does not hamper the economical feasibility and impact of the proposed CHP plant. The PBP remains below 10 years for all the considered cases and is incremented by 1 year with respect to cost minimization in the worst cases. The effect of $\tau$ and HoP is fundamentally the same compared to economic optimization, with colder climates being favored both in terms of cost and PEC relative reduction and with a larger economic impact for lower $\tau$. Notably also PEC minimization yields significant reductions of the energy cost, in the range $[18 \%, 40 \%]$. However, the increased efficiency entails a reduction of the cash flow with respect to the minimum cost control strategy. Such a reduction is comprised between $2.5 \%$ for the clinic and cold climate and $20 \%$ for the hotel and hot climate. We also note that the economic penalty is more relevant for hot climates, due to the low heat demand that reduces the effectiveness of cogeneration.

Overall, the clinic still appears to be the most convenient compromise, with an unvaried PBP of 4 years and a significant relative $\mathrm{PEC}$ and cost reduction.

\subsection{Effects of the surrounding energy system: prices and PEFs}

The encompassing energy system contributes to the determination of the CHP plant optimal control strategy and to its economic and energy outcomes through the unit energy prices and electricity PEF. The impact of these factors is here evaluated by assuming the same energy demand profiles studied in the previous sections applied to users located in Europe. This allows isolating the effects of the energy costs and of the grid efficiency. This hypothesis underlies the assumption that European and American consumers have comparable behaviors, and that buildings are technologically similar.

According to the data reported in Table 4, the energy prices in Europe are significantly larger than in the US [74-76]. The European NG is about $75 \%$ more expensive compared to the US one, for both residential and commercial users. For electricity, such a difference varies between $40 \%$, for commercial users, and $70 \%$, for residential consumers. For the commercial energy demand, the ratio between electricity and $\mathrm{NG}$ price in the EU is about $20 \%$ lower than in the US. On the contrary, for residential users, such a ratio is $12 \%$ larger in the EU compared to US, despite the lower PEF of the electricity.

As a consequence, the total expenditure for the energy supply in the EU is larger than in the US with and without the CHP plant, as evidenced by comparing the results shown in Figure 12(a) to those reported in Figure 14(a). We also note that the CHP plant is more sensitive to energy price variations with respect to the reference scenario. In fact, if we refer to the economic optimization, the total cost increases from about $45 \%$ to $50 \%$ for separate production assuming the EU prices, while with the CHP plant, such an increment is between $50 \%$ and $70 \%$. Such a behavior is explained considering that that NG cost variation is much larger compared to electricity one. Thereafter, decentralized electricity production that relies on NG as the primary energy source is disadvantaged. This also determines a moderate reduction of the utilization of the FC (compare Figure 12(c) to Figure 14(c)), whose set point is reduced to improve the efficiency (see Figure 3 ) and to reduce the cost of locally produced electricity. Nevertheless, the EU scenarios have a larger cash flow compared to the US ones thus, improving the investment feasibility.

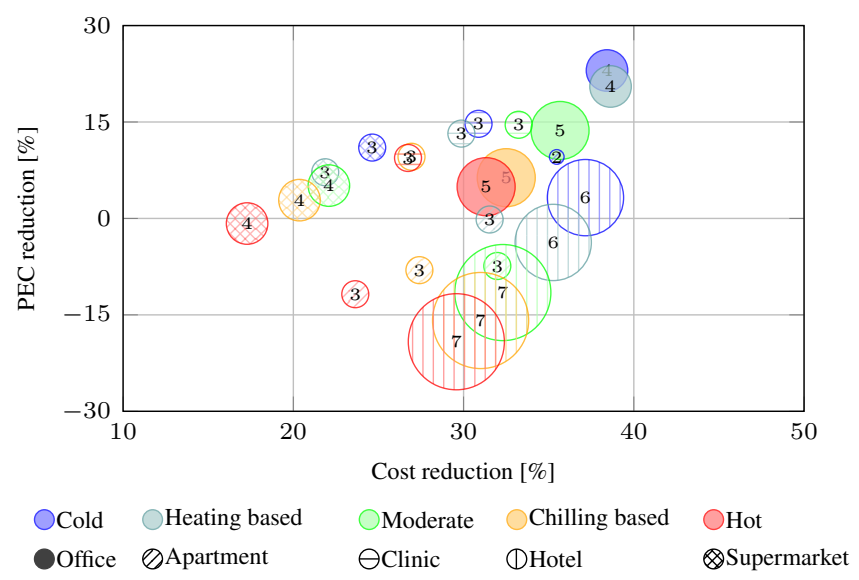

Figure 18: Comparison between the different scenarios for the minimum cost strategy and the EU energy market: the area of the circles is proportional to the pay back period and the center of the circles defines relative cost and PEC reduction.

Figure 18 summarizes the energy and economic impact of cogeneration obtained through economic optimization for all the considered combinations of energy demand and climatic condition. Differently for the US scenarios, in several EU scenarios, economic optimization yields an increment of the PEC with respect to the reference scenario (see also Figure 14). Such a behavior is explained by the fact that the PEF of the locally produced electricity is always larger compared to $\mathrm{PEF}_{\text {grid }}$. Thereafter, heat recovery is necessary to guarantee the total efficiency of the CHP plant. In fact, if the power plant control strategy minimizes costs, CHP consistently increments the PEC in hotter climates (i.e. lower HoP), due to the lack of heat recovery. 
If we compare the results reported in Figure 12 to those of Figure 14 we note that also in the EU the PEC variation is significantly lower compared to US also for the other cases. Such a variation is comprised between $40 \%$ and $230 \%$.

Due to the larger energy cost, the PBP in Europe is consistently lower than in the US: in general, the initial investment is payed back one year earlier, except for the hotel energy demand profile, as clearly detectable by comparing Figure 16 to Figure 18. Nevertheless, the economic impact of the CHP plant is slightly lower in Europe, being the relative cost variation reduced of an amount comprised between $5 \%$ (apartment district) and $30 \%$ (hotel building). The clinic building might still be considered the most favorable test case for the proposed CHP plant with a PEC reduction steadily around $15 \%$, a cost reduction comprised between $25 \%$ and $35 \%$ and a PBP of about 3 years for all the climatic conditions. The least favorable building is the hotel, despite a positive cash flow between $30 \%$ and $37 \%$ of the energy cost in the reference scenario. In fact, with the hotel energy demand profile we observe the largest PBP, comprised between 6 and 7 years, and a negative PEC variation for all the climates, except for the cold one.

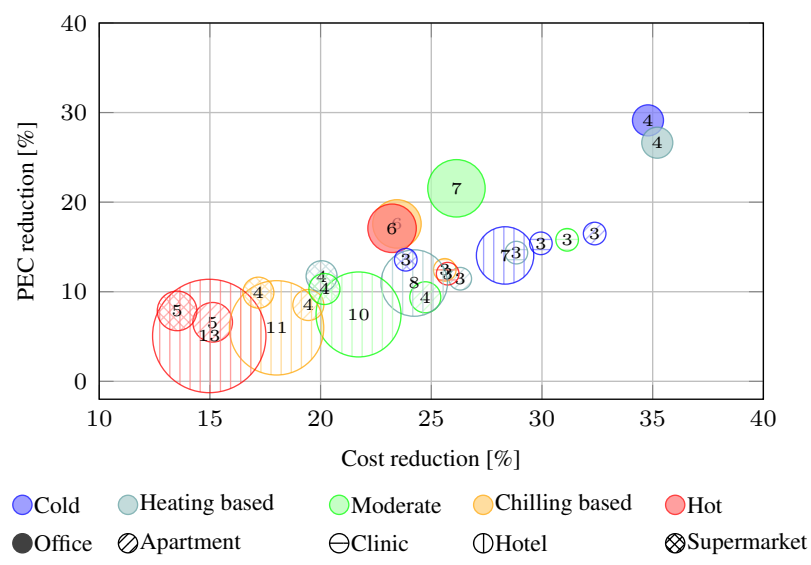

Figure 19: Comparison between the different scenarios for the minimum PEC strategy and the UE energy market: the area of the circles is proportional to the pay back period and the center of the circles defines relative cost and PEC reduction.

Evaluating the effects of a more environmentally aware control strategy is particularly relevant in the EU scenario where cogeneration, through the proposed plant, is not synonymous of PEC reduction, as explained above. The results relative to PEC minimization with the European energy prices and PEFs are reported in Figure 15 and in Figure 19. Such a control strategy guarantees a significant reduction of the PEC, comprised between $7 \%$ and $30 \%$ with respect to the reference scenario. This results into an improvement of the performance of the CHP plant comprised between $10 \%$ for the clinic and $110 \%$ for the supermarket. Notably, such a dramatic variation in the energy performance of the power plant is obtained without any technological improvement of the plant nor any variation of its design characteristics, but only through a different control strategy.

PEC minimization also guarantees a positive cash flow for all the considered case. Nevertheless the relative cost variation is reduced with respect to cost minimization. In particular the cash flow reduction is comprised between $4 \%$ and $20 \%$. The PBP is significantly increased only for the hotel energy demand profile, which, on the other hand, was the least favorable energy demand.

\subsection{Analysis of the potential markets for PEM based CHP}

In this paper, besides analyzing the performance of a fuel cell based CHP system, we highlight the effectiveness of utilizing the optimization methodology proposed in $[53,55]$ to realize a strong, reliable, and complete business case. Cash flow, energy consumption, pollutant emissions, and PBP are some of the outputs of the proposed methodology that can be utilized to evaluate the potential of the proposed technology in a real energy management scenario.

In this respect, the results reported herein show that the clinic is the most suited environment for the adoption of such a PEM based CHP plant. Significant economies and energy saving could be obtained also in the residential sector, which certainly represents a wider market. In fact, more that 1 Million new residential units are constructed every year in the sole US [84]. Considering that the plant in study is able to satisfy the energy demand of 40-60 families, the potential market size may be estimated in 20000 units every year. For such a production volume the DOE [49] estimates an installed cost well below $1000 \$ / \mathrm{kW}$. Although this estimation may be considered too optimistic [38], such a production volume will positively impact the fuel cell production costs.

\section{Conclusions}

In this paper we assess the effective performance of a 100 $\mathrm{kW}$ CHP plant that utilizes a PEM fuel cell as the prime mover in realistic energy management scenarios. The efficiency of the energy system at different operating conditions is evaluated though a numerical model validated with experimental data [59]. The investment cost is assumed to be $2000 € / \mathrm{kW}$ and the energy system performance is calculated for different energy demand scenarios. In particular, we assumed that the power plant must satisfy the energy demand of five different buildings with an electricity demand between $60 \mathrm{~kW}$ and $200 \mathrm{~kW}$ : a medium office, an apartment district, a clinic, a small hotel, and a supermarket. Moreover, six different climatic zones based on heating and cooling requirements are considered: cold climate, heating based climate, combined climate, moderate climate, cooling based climate, and hot climate. The analysis is carried out in 9 average working and 9 average non-working days, representative of the whole year. The energy demand profiles are constructed for each combination of building and climatic zone based on heat and cooling demand levels and are considered. The energy system is always operated with an optimal control strategy assuming two possible management policies: cost minimization and primary Energy Consumption (PEC) minimization. The technical and economical results are compared to a reference scenario where electricity is acquired from the grid and heat is locally produced through a natural gas 
boiler. To this aim, we consider two different electricity and natural gas markets, Europe and United States.

The results show that the proposed CHP plant is economically sustainable for most of the considered scenarios and that it is effective in reducing the energy costs and the PEC. The clinic is the most suited environment for the adoption of such a PEM based CHP plant, while the residential sector might represent the wider market.

More in detail, the PBP is significantly affected by the unit energy prices and by the building type. In particular, the PBP is much lower in Europe (i.e. between 3 and 13 years), where the energy prices are larger compared to US. Conversely, the climate largely determines the relative PEC and cost reduction. In general cold climates yield larger positive cash flows (between $30 \mathrm{k} €$ and $100 \mathrm{k} €$ ) and larger PEC reductions (up to 40\%), as they facilitates the thermal recovery improving the effectiveness of the CHP plant. Such a result highlights the opportunity to study technical solutions to exploit the heat recovery also during the hot seasons, for example through single effect absorption chillers. To this aim, heat recovery from the fuel processor might be considered due to the relatively low operating temperature of the FC. Such a plant configuration will be the object of future research.

The choice of the management policy (i.e. economic or PEC optimization) does not significantly impact the PBP. Nevertheless it influences the energy consumption and the cash flow. In fact, in the US scenario the economic minimization is relatively coherent with the PEC minimization, while with the European prices the PEC reduction with respect to the reference scenario is not granted by the economically optimal control strategy. Reducing the PEC with respect to the businesses as usual is more difficult in the EU due to the lower primary energy factor of the electrical grid. However, significant PEC reductions can be obtained also in the EU scenario (between $5 \%$ and $30 \%$ ) by utilizing the minimum PEC management with a moderate reduction of the economic benefit with respect to cost minimization. We note that PEC optimization always yields a positive cash flow. AS a result, switching the management policies of the CHP plants towards PEC minimization rather than economically optimal control strategies should be seriously considered an option to reduce the global energy consumption, in particular for European like scenarios.

\section{Acknowledgment}

This project has received funding from the Fuel Cells and Hydrogen Joint Undertaking under grant agreement $N^{\circ} 671396$. This Joint Undertaking receives support from the European Union's Horizon 2020 research and innovation programme and United Kingdom, Germany, Greece, Croatia, Italy, Switzerland, Norway. Swiss partners are funded by the State Secretariat for Education, Research and Innovation of the Swiss Confederation.

\section{References}

[1] E. Jannelli, M. Minutillo, A. Perna, Analyzing microcogeneration systems based on LT-PEMFC and HT-PEMFC by energy balances, Applied Energy 108 (2013) 82-91.

[2] F. Cappa, A. L. Facci, S. Ubertini, Proton exchange membrane fuel cell for cooperating households: A convenient combined heat and power solution for residential applications, Energy 90 (2015) 1229-1238.

[3] S. Pellegrino, A. Lanzini, P. Leone, Techno-economic and policy requirements for the market-entry of the fuel cell micro-CHP system in the residential sector, Applied Energy 143 (2015) 370-382.

[4] A. Adam, E. S. Fraga, D. J. Brett, Options for residential building services design using fuel cell based micro-CHP and the potential for heat integration, Applied Energy 138 (2015) 685-694.

[5] F. Calise, R. D. Figaj, N. Massarotti, A. Mauro, L. Vanoli, Polygeneration system based on pemfc, cpvt and electrolyzer: Dynamic simulation and energetic and economic analysis, Applied Energy 192 (Supplement C) (2017) $530-542$.

[6] E. Jannelli, M. Minutillo, R. Cozzolino, G. Falcucci, Thermodynamic performance assessment of a small size cchp (combined cooling heating and power) system with numerical models, Energy 65 (2014) 240-249.

[7] J. Sadhukhan, Distributed and micro-generation from biogas and agricultural application of sewage sludge: Comparative environmental performance analysis using life cycle approaches, Applied Energy 122 (2014) 196-206.

[8] F. C. Today, The fuel cell industry review 2013, Tech. rep., Fuel Cell Today (2013).

URL http://www. fuelcelltoday.com/media/1889744/ fct_review_2013.pdf.

[9] N. Sammes, R. Boersma, Small-scale fuel cells for residential applications, Journal of Power Sources 86 (1â2) (2000) 98 - 110.

[10] F. Baratto, U. M. Diwekar, D. Manca, Impacts assessment and tradeoffs of fuel cell based auxiliary power units: part ii. environmental and health impacts, lca, and multi-objective optimization, Journal of power sources 139 (1) (2005) 214-222.

[11] S. Singhal, Advances in solid oxide fuel cell technology, Solid state ionics 135 (1) (2000) 305-313.

[12] H. Onovwiona, V. Ugursal, Residential cogeneration systems: review of the current technology, Renewable and Sustainable Energy Reviews 10 (5) (2006) $389-431$.

[13] J. Lagorse, M. G. Simoes, A. Miraoui, P. Costerg, Energy cost analysis of a solar-hydrogen hybrid energy system for stand-alone applications, International journal of hydrogen energy 33 (12) (2008) 2871-2879.

[14] B. C. Steele, Fuel-cell technology: running on natural gas, Nature 400 (6745) (1999) 619-621.

[15] G. Falcucci, E. Jannelli, M. Minutillo, S. Ubertini, J. Han, S. Yoon, S. Nam, Integrated numerical and experimental study of a mcfc-plasma gasifier energy system, Applied Energy 97 (2012) 734 - 742.

[16] W. Zhou, H. Yang, M. Rissanen, B. Nygren, J. Yan, Decrease of energy demand for bioethanol-based polygeneration system through case study, Applied Energy 95 (2012) 305 - 311.

[17] M. Moneti, A. D. Carlo, E. Bocci, P. Foscolo, M. Villarini, M. Carlini, Influence of the main gasifier parameters on a real system for hydrogen production from biomass, International Journal of Hydrogen Energy 41 (28) (2016) $11965-11973$.

[18] R. Cozzolino, L. Tribioli, G. Bella, Power management of a hybrid renewable system for artificial islands: A case study, Energy 106 (2016) 774-789.

[19] Y. Zhang, A. Lundblad, P. E. Campana, J. Yan, Comparative study of battery storage and hydrogen storage to increase photovoltaic selfsufficiency in a residential building of sweden, Energy Procedia 103 (2016) 268-273.

[20] G. Chicco, P. Mancarella, Distributed multi-generation: A comprehensive view, Renewable and Sustainable Energy Reviews 13 (3) (2009) 535 551 .

[21] International Energy Agengy, Distributed Generation in Liberalised Electricity Markets (2002).

[22] K. Lau, M. Yousof, S. Arshad, M. Anwari, A. Yatim, Performance analysis of hybrid photovoltaic/diesel energy system under malaysian conditions, Energy 35 (8) (2010) 3245 - 3255.

[23] A. Franco, P. Salza, Strategies for optimal penetration of intermittent re- 
newables in complex energy systems based on techno-operational objectives, Renewable Energy 36 (2) (2011) 743 - 753.

[24] M. Naqvi, E. Dahlquist, J. Yan, Complementing existing chp plants using biomass for production of hydrogen and burning the residual gas in a chp boiler, Biofuels (2016) 1-9.

[25] L. Tribioli, R. Cozzolino, D. Chiappini, P. Iora, Energy management of a plug-in fuel cell/battery hybrid vehicle with on-board fuel processing, Applied Energy 184 (2016) 140 - 154.

[26] Japan's backing to fuel-cell cars could benefit toyota's new model. URL https: / / www. forbes.com/sites/great speculations / 2014/06/26/japans-backing-to-fuel-cell-cars-could -benefit-toyotas-new-model/\#5d784a50587

[27] Japan plans ample support for fuel cell car technology. URL http: //uk.reuters.com/article/us-autosfuelcells-japan-idUKKBNOEU23H20140619

[28] C. C. Chan, The state of the art of electric, hybrid, and fuel cell vehicles, Proceedings of the IEEE 95 (4) (2007) 704-718

[29] European Commission, Buildings (2016 (accessed March 11, 2016)). URL https://ec.europa.eu/energy/en/topics/energy -efficiency/buildings

[30] A. Afram, F. Janabi-Sharifi, Theory and applications of HVAC control systems-a review of model predictive control (MPC), Building and Environment 72 (2014) 343-355.

[31] US Department of Energy, Buildings energy data book (2012 (accessed March 11, 2016))

URL http: / /buildingsdatabook. eren.doe.gov/ ChapterIntro2.aspx

[32] I. E. Agency, Combined heat and power evaluating the benefits of greater global investment (2008).

[33] Ballard, ClearGen specification sheet.

URL http: / / pdf.directindustry.com/pdf/ballard/ cleargen-multi-mw-systems/22779-383697.html

[34] Ballard, Economics of Fuel Cell Solutions for Backup Power. URL http: / / ballard.com/files/PDF/Backup_Power/ BUP_EmrgncyEcon_EGen_091712-01.pdf

[35] Micro-CHP, PEM fuel cells.

URL http: / /www.microchap.info/pem_fuel_cells.htm

[36] Doosan, PuroCell Model 400

URL http: / / www.doosanfuelcell.com/attach_files/link / PureCell\%20Model\%20400\%20Datasheet.pdf

[37] Elcore $2400 \mathrm{Max}$ - das Komplettpaket.

URL http: //www.elcore.com/elcore-energiesysteme/ elcore-2400-max/

[38] I. Staffell, R. Green, The cost of domestic fuel cell micro-chp systems, International Journal of hydrogen energy 38 (2) (2013) 1088-1102.

[39] Inhouse engineering, Fuel cell $\mu$ CHP system inhouse5000+.

URL https: / / www . inhouse-engineering.com/en/fuel-cell -systems/products/fuel-cell-chp-systeminhouse 5000 plus/

[40] Tropical Green technologies, 5 kW Hydrogeno Fuel Cell Generator. URL http: //www.tropical.gr/fuel-cell-powergenerators/5kw-fc-power-generator.html $\sharp 5 \mathrm{kw} \_2$

[41] Fuel cell boiler Vitovalor 300-P

URL http://www.viessmann.co.uk/en/residential -buildings/combined-heat-and-power-generation/ micro-chp-unit-based-on-a-fuel-cell/vitovalor$300 \mathrm{p} \cdot \mathrm{html}$

[42] Fuel cells and hydrogen joint undertaking (FCH JU) multi-annual work plan 2014-2020.

URL http: / / www. fch.europa.eu/sites/default/files/

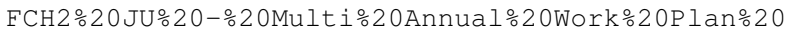
$-\div 20$ MAWP $\div 20 \% 28$ ID $20623483 \div 29 . p d f$

[43] D. Carter, Fuel cell residential micro-CHP developments in Japan, Tech rep., Fuel Cell Today (2012).

URL http: //www fuelcelltoday.com/media/1597029/ 29-02-12_ene-farm.pdf

[44] F. C. Today, 2010 survey of korea.

URL http: / / www. fuelcelltoday.com/media/1156544/ 2010_survey_of_korea.pdf

[45] Callux residential project under way in germany, Fuel Cells Bulletin 2008 (11) (2008) $3-4$.
[46] Fc district new $\mu$-CHP network technologies for energy efficient and sustainable districts.

URL http: / / www. fc-district.eu/project.html

[47] ene.field. fuel cells $x$ combined heat and power.

URL http: //enefield.eu/

[48] J. Spendelow, J. Marcinkoski, D. Papageorgopoulos, Micro CHP fuel cell system targets (2012)

URL https: / / www. hydrogen. energy.gov/pdfs / 11016_micro_chp_target.pdf

[49] B. D. James, A. B. Spisak, W. G. Colella, Manufacturing cost analysis of stationary fuel cell systems, Tech. rep., Strategic Analysis (2012).

[50] M. Wei, S. Smith, M. Sohn, Experience curve development and cost reduction disaggregation for fuel cell markets in japan and the us, Applied Energy 191 (2017) 346-357.

[51] European Commission, CORDIS the Community Research and Development Information Service.

URL http: / / cordis.europa.eu/project/rcn/197929_ en.html

[52] AutoRe (2016)

URL http: / / www . autore-fch. com/concept-and-vision

[53] A. L. Facci, L. Andreassi, S. Ubertini, Optimization of chcp (combined heat power and cooling) systems operation strategy using dynamic programming, Energy 66 (2014) 387-400.

[54] A. L. Facci, L. Andreassi, F. Martini, S. Ubertini, Comparing energy and cost optimization in distributed energy systems management, Journal of Energy Resources Technology 136 (3) (2014) 032001.

[55] A. L. Facci, L. Andreassi, S. Ubertini, E. Sciubba, Analysis of the influence of thermal energy storage on the optimal management of a trigeneration plant, Energy Procedia 45 (2014) 1295-1304.

[56] G. D. Marcoberardino, L. Roses, G. Manzolini, Technical assessment of a micro-cogeneration system based on polymer electrolyte membrane fuel cell and fluidized bed autothermal reformer, Applied Energy 162 (Supplement C) (2016) 231 - 244.

[57] European Patent 94600005.6/13.07.94. U.S.A. Patent No. 6, 605376 Aug. 12.2003.

[58] A. Piga, X. E. Verykios, An advanced reactor configuration for the partial oxidation of methane to synthesis gas, Catalysis today 60 (1) (2000) 63 71.

[59] A. L. Facci, G. Loreti, S. Ubertini, F. Barbir, T. Chalkidis, R.-P. Eßling, T. Peters, E. Skoufa, R. Bove, Numerical assessment of an automotive derivative CHPfuel cell system, in: Proceedings of the 8'th International Conference on Applied Energy, Elsevier, 2016.

[60] Aspen, Aspenplus (2016).

URL http: / / www. aspentech.com/products/engineering /aspen-plus /

[61] E. Fabrizio, M. Filippi, J. Virgone, An hourly modelling framework for the assessment of energy sources exploitation and energy converters selection and sizing in buildings, Energy and Buildings 41 (10) (2009) 1037-1050.

[62] IEA-IRENA, Thermal Energy Storage Technology Brief (2013). URL www. irena.org/Pubblications

[63] A. Hawkes, M. Leach, Cost-effective operating strategy for residential micro-combined heat and power, Energy 32 (5) (2007) 711-723.

[64] L. Andreassi, M. Ciminelli, M. Feola, S. Ubertini, Innovative method for energy management: Modelling and optimal operation of energy systems, Energy and Buildings 41 (4) (2009) 436-444.

[65] D. Chiappini, A. L. Facci, L. Tribioli, S. Ubertini, SOFC management in distributed energy systems, Journal of Fuel Cell Science and Technology 8 (3).

[66] L. Tribioli, R. Cozzolino, L. Evangelisti, G. Bella, Energy management of an off-grid hybrid power plant with multiple energy storage systems, Energies 9 (8) (2016) 661.

[67] Z. Liu, Y. Chen, R. Zhuo, H. Jia, Energy storage capacity optimization for autonomy microgrid considering chp and ev scheduling, Applied Energy 210 (2018) 1113-1125.

[68] M. Schicktanz, J. Wapler, H.-M. Henning, Primary energy and economic analysis of combined heating, cooling and power systems, Energy 36 (1) (2011) 575-585

[69] A. Fumarola, L. Tribioli, F. Martini, Methodology procedure for hybrid electric vehicles design, in: Proceedings of International Conference on Engines and Vehicles, SAE Conference, 2011. 
[70] V. Marano, G. Rizzo, F. A. Tiano, Application of dynamic programming to the optimal management of a hybrid power plant with wind turbines, photovoltaic panels and compressed air energy storage, Applied Energy 97 (0) (2012) 849-859, energy Solutions for a Sustainable World - Proceedings of the Third International Conference on Applied Energy, May 16-18, 2011 - Perugia, Italy.

[71] M. Khalid, R. Aguilera, A. Savkin, V. Agelidis, On maximizing profit of wind-battery supported power station based on wind power and energy price forecasting, Applied Energy 211 (2018) 764-773.

[72] M. J. Laustsen, Energy efficiency requirements in building codes, energy efficiency policies for new buildings (2008).

[73] Office of Energy Efficiency and Renewable Energy, Commercial reference buildings, http://energy.gov/eere/buildings/commercial-referencebuildings (November 2016).

[74] Eurostat, Eurostat, your key to european statistics (2016).

URL http: / / ec. europa.eu/eurostat/web/energy/data/ database

[75] U.S. Energy Information Administration, Electric power monthly (2016).

URL https: //www.eia.gov/electricity/monthly/ epm_table_grapher.cfm?t=epmt_5_6_a

[76] U.S. Energy Information Administration, Natural gas (2016).

URL https: / / www.eia.gov/dnav/ng/ ng_pri_sum_dcu_sAz_a.htm

[77] U. R. Fritsche, H.-W. Greß, Development of the primary energy factor of electricity generation in the eu- 28 from 2010-2013, Tech. rep., International Institute for Sustainability Analysis and Strategy (IINAS), prepared for the European Heat Pump Association (EHPA) (2015).

[78] EIA Independent statistics and analysis, U.S. Energy Information Administration, Annual energy review (2016).

URL https: //www.eia.gov/totalenergy/data/annual/ index.php

[79] Energy Star Portfolio Manager, Source energy (2013).

URL https: //portfoliomanager.energystar.gov/pdf / reference/Source\%20Energy.pdf

[80] A. L. Facci, V. Cigolotti, E. Jannelli, S. Ubertini, Technical and economic assessment of a sofc-based energy system for combined cooling, heating and power, Applied Energy.

[81] M. Biezma, J. San Cristobal, Investment criteria for the selection of cogeneration plants-a state of the art review, Applied Thermal Engineering $26(5-6)$ (2006) $583-588$.

[82] Y. Wang, K. S. Chen, J. Mishler, S. C. Cho, X. C. Adroher, A review of polymer electrolyte membrane fuel cells: Technology, applications, and needs on fundamental research, Applied Energy 88 (4) (2011) 981 - 1007.

[83] A. Chandan, M. Hattenberger, A. El-kharouf, S. Du, A. Dhir, V. Self, B. G. Pollet, A. Ingram, W. Bujalski, High temperature (HT) polymer electrolyte membrane fuel cells (PEMFC) - a review, Journal of Power Sources 231 (2013) $264-278$.

[84] The U.S. Census Bureau and the U.S. De partment of Housing and Urban Developmen, Monthly new residential construction, february 2017. URL https: / / www. census.gov/construction/nrc/pdf / newresconst.pdf 